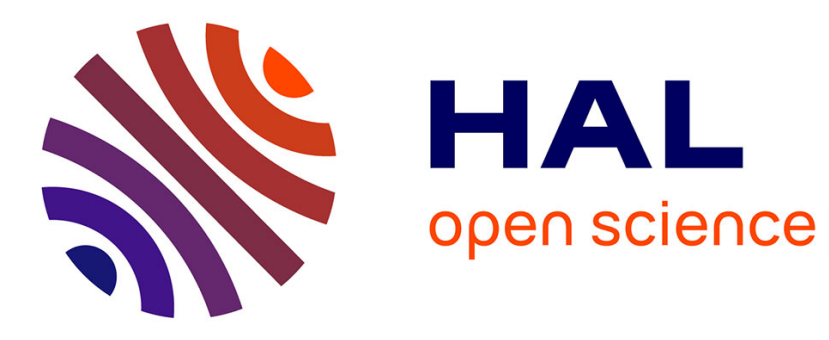

\title{
SST patterns and dynamics of the southern Senegal-Gambia upwelling center
}

Siny Ndoye, Xavier Capet, Philippe Estrade, Bamol Sow, Dominique

Dagorne, Alban Lazar, Amadou Thierno Gaye, Patrice Brehmer

\section{- To cite this version:}

Siny Ndoye, Xavier Capet, Philippe Estrade, Bamol Sow, Dominique Dagorne, et al.. SST patterns and dynamics of the southern Senegal-Gambia upwelling center. Journal of Geophysical Research. Oceans, 2014, 119 (12), pp.8315-8335. 10.1002/2014JC010242 . hal-01103312

\section{HAL Id: hal-01103312 \\ https: / hal.sorbonne-universite.fr/hal-01103312}

Submitted on 14 Jan 2015

HAL is a multi-disciplinary open access archive for the deposit and dissemination of scientific research documents, whether they are published or not. The documents may come from teaching and research institutions in France or abroad, or from public or private research centers.
L'archive ouverte pluridisciplinaire HAL, est destinée au dépôt et à la diffusion de documents scientifiques de niveau recherche, publiés ou non, émanant des établissements d'enseignement et de recherche français ou étrangers, des laboratoires publics ou privés. 


\title{
Journal of Geophysical Research: Oceans
}

\section{RESEARCH ARTICLE SST patterns and dynamics of the southern Senegal-Gambia 10.1002/2014JC010242 upwelling center}

Key Points:

- Analysis of SST and wind reveals the stability of the SSUC dynamical

functioning

- Analysis of SST reveals large amplitude of the nearshore diurnal cycle

- Improved SSUC dynamical description by identification of recurrent features

Correspondence to: S. Ndoye,

Siny.Ndoye@locean-ipsl.upmc.fr

Citation:

Ndoye, S., X. Capet, P. Estrade, B. Sow, D. Dagorne, A. Lazar, A. Gaye, and P. Brehmer (2014), SST patterns and dynamics of the southern SenegalGambia upwelling center, J. Geophys. Res. Oceans, 119, doi:10.1002/ 2014JC010242.

\author{
S. Ndoye1,2, X. Capet'2, P. Estrade1, B. Sow ${ }^{3}$, D. Dagorne', A. Lazar², A. Gaye', and P. Brehmer5 \\ ${ }^{1}$ Laboratoire de Physique de l'Atmosphère et de I'Ocean Siméon Fongang, ESP/UCAD, Dakar, Senegal, ${ }^{2} \mathrm{CNRS}-\mathrm{IRD}-$ \\ Sorbonne Universités, UPMC, Univ Paris 06, MNHN, LOCEAN Laboratory, Paris, France, ${ }^{3}$ Laboratoire d'Océanographie, des \\ Sciences de I'Environnement et du Climat, Université de Ziguinchor, Ziguinchor, Senegal, ${ }^{4}$ Institut de Recherche pour le \\ Développement, Institut de Recherche pour le Développement, US Imago, Plouzané, France, ${ }^{5}$ Institut Sénégalais de \\ Recherche Agronomique, Centre de Recherche Océanographique Dakar-Thiaroye, Dakar, Senegal
}

Abstract The southern end of the Canary current system comprises of an original upwelling center that has so far received little attention, the Southern Senegal-Gambia Upwelling Center (SSUC). We investigate its dynamical functioning by taking advantage of favorable conditions in terms of limited cloud coverage. Analyses and careful examinations of over 1500 satellite images of sea surface temperature scenes contextualized with respect to wind conditions confirm the regularity and stability of the SSUC dynamical functioning (as manifested by the recurrence and persistence of particular SST patterns). The analyses also reveal subtle aspects of its upwelling structure: shelf break cooling of surface waters consistent with internal tide breaking/mixing; complex interplay between local upwelling and the Mauritanian current off the Cape Verde headland; complexity of the inner-shelf/mid shelf frontal transition. The amplitude of the diurnal cycle suggests that large uncertainties exist in the SSUC heat budget. The studies limitations underscore the need for continuous in situ measurement in the SSUC, particularly of winds.

\section{Introduction}

A major subdivision of the Canary current systems is marked by the Cape Verde frontal zone, which approximately runs between Cape Blanc ( $21^{\circ} \mathrm{N}$, Mauritania) and the Cape Verde archipelago [Barton, 1998]. Important distinctions exist in terms of the large-scale circulation and water mass properties on either side of this front. North of the front the Canary current carries salty North Atlantic Central Water along the main return branch of the North Atlantic subtropical gyre. South of the front, fresher South Atlantic Central Water is found and the mean flow is strongly affected by positive wind stress curl forcing [Bakun and Nelson, 1991]: the regional-scale circulation is cyclonic with a poleward boundary current, the Mauritanian current (hereafter MC), whose extension at depth forms the slope undercurrent typical of upwelling systems [PeñaIzquierdo et al., 2012; Barton, 1989]. The MC connects with the complex equatorial current system and this connection involves a quasi-stationary cyclonic feature, the Guinea dome (more details can be found in Barton [1998] and Arístegui et al. [2009]; see also Figure 1).

The coastal domain of the southern Canary current system encompassing southern Mauritania, Senegal, and Gambia has received little attention for at least two decades, especially in terms of the dynamics [Arístegui et al., 2009]. This is despite the high levels of primary production observed there; its role as nursery ground for small pelagic fish and general socioeconomic importance [Cury and Roy, 1991]. Thus, the importance of the region raises widespread concerns that the ecosystem could be fragile to global changes and climate variability.

In this study, we focus on the upwelling center off southern Senegal and Gambia $\left(\sim 13^{\circ} \mathrm{N}-14^{\circ} 40^{\prime} \mathrm{N}\right.$; hereafter SSUC), which has interesting physical peculiarities and plays a key ecological role [Roy et al., 1989]. The main originality of the SSUC compared to other upwelling centers stems from its continental shelf that is broad and shallow, i.e., 20-30 m over tens of kilometers (Figure 2a). As a consequence, typical upwelling events (wind speeds above 5-6 $\mathrm{m} \mathrm{s}^{-1}$ ) are associated with an inner-shelf length scale of $\sim 20 \mathrm{~km}$ or more. Here our definition of the inner shelf follows Lentz [1994] [see also Lentz and Fewings, 2012, and references therein]. It refers to the part of the shelf where water depth is so small that the top and bottom boundary 


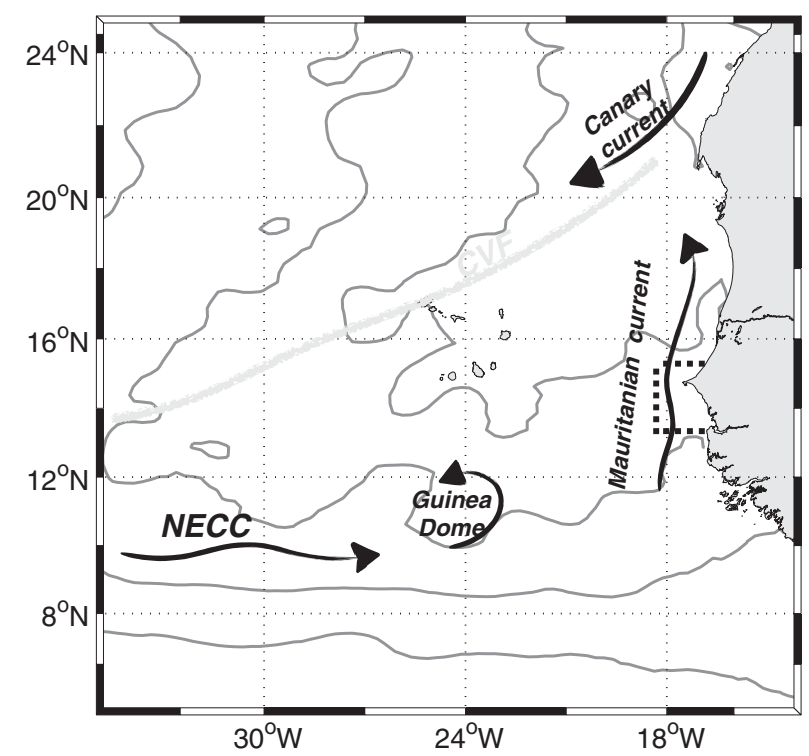

Figure 1. Ssalto-Duacs long-term mean sea level over the northeastern tropical Atlantic (gray contours every $4 \mathrm{~cm}$, increasing southward) superimposed on a schematic representation of the main circulation features of the region including the North Equatorial counter-current (NECC) and the Cape Verde Frontal zone (CVF, thick gray). Our domain of focus (e.g., shown in Figure 2a) is delineated with dotted lines. layers are not separated. A dynamical implication is that wind stress is essentially balanced by bottom friction so that offshore Ekman transport is reduced or even vanishes over a wide coastal strip in the SSUC [Estrade et al., 2008]. Direct manifestations of this have been reported on sea surface temperature (SST) satellite images such as Figure 2 (see also climatological SST in Figure 3). During part of the upwelling season (which generally starts in October and ends in late May to early June), the normal state of the system comprises the classical upwelling front but also a welldefined inner-shelf front that separates cold recently upwelled waters from nearshore warmer waters [Demarcq and Faure, 2000]. These SST patterns have

been interpreted in terms of enhanced retention of nearshore waters, although in situ measurements are lacking to corroborate this (in contrast to the situation in the California or Benguela current where nearshore retention has been the subject of several observational programs [Roughan et al., 2006; Lamb and Peterson, 2005; Graham and Largier, 1997]).

More generally, SST images of the SSUC tend to contrast with the classical images of other known systems. During the upwelling season, they exhibit numerous patterns and features that seem repetitive and/or very persistent in time. Filaments are often absent or broad with edges smoother than can be observed, e.g., in the California current system [Ramp et al., 1991]. An explanation valid for the entire Canary system attributes this weak mesoscale variability and frontality to the compensations effects between salinity and temperature [Marchesiello and Estrade, 2009], which is stronger than in other systems.

Because of reduced cloud coverage during the upwelling season (particularly between February and May) the SSUC is a place where a considerable amount of high-resolution SST information is available. The main objective of this study is to advance our current understanding of the dynamical functioning of the SSUC during the upwelling season, by an in-depth analysis of the Moderate Resolution Imaging Spectroradiometer "MODIS" SST data set.

Wind being the main driving force underlying the SST patterns of upwelling, we strive to connect its structure and fluctuations to those of the SST. (Note that, despite several nearby river estuaries (Gambia River at $13^{\circ} 30^{\prime} \mathrm{N}$; Casamance farther south at $\sim 12^{\circ} 35^{\prime} \mathrm{N}$ ) the SSUC is not subjected to significant river outflows during the essentially rain-free upwelling season.) The SSUC is not rich in wind measurements and winds from available global reanalyses have significant deficiencies over the SSUC (S. Ndoye et al., manuscript in preparation, 2015) [see also Capet et al., 2004]. Our two main sources are QuikSCAT scatterometer measurements and the Yoff weather station at Dakar Airport (Senegal, DWS). They are complemented with observations at the Banjul (Gambia, BWS) weather station and also wind measurements made during two field experiments on R/V Suroît (7-17 March 2012) and R/V Antéa (21 February 2013 to 18 March 2013). QuikSCAT winds are available at best twice a day and are unable to resolve intradaily fluctuations, including the daily cycle. Daily QuikSCAT fields may thus be occasionally biased by short-term wind bursts or lulls which would blur possible wind-SST relations. For our purpose, the hourly temporal resolution of DWS winds is thus preferable. On the other hand, it is unclear whether the wind measured at Dakar airport is representative of the winds over the SSUC, which extends tens to a hundred kilometers to the south. Wind in regions with headlands similar to Cape Verde headland can exhibit fine-scale variability, but accompanying topographic relief is generally 


\section{QAGU Journal of Geophysical Research: Oceans}
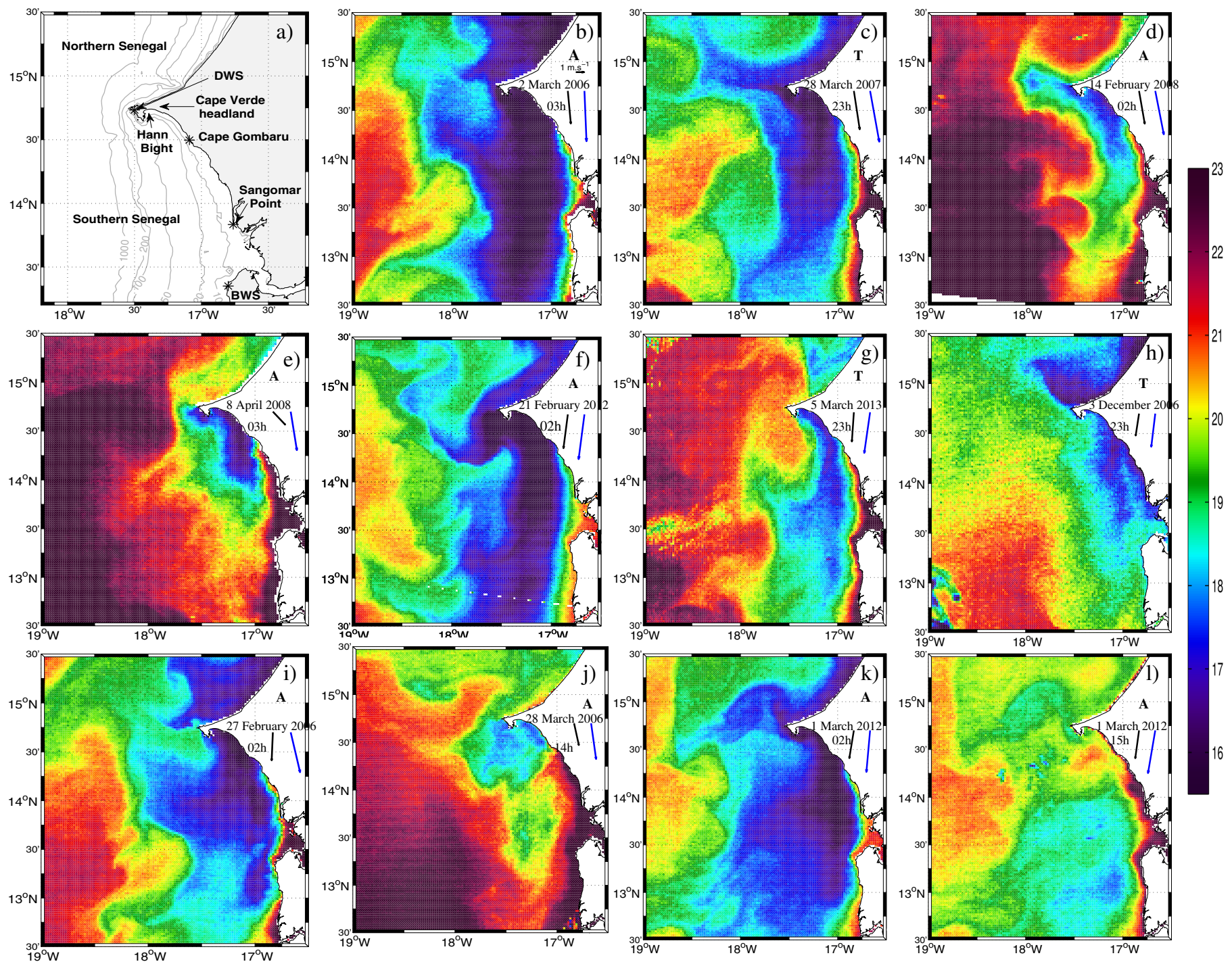

Figure 2. (a) Presentation of the area and important geographical/meteorological locations used in the study including the Dakar and Banjul weather stations (DWS and BWS, respec-

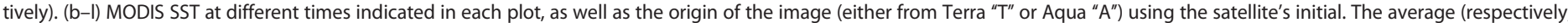

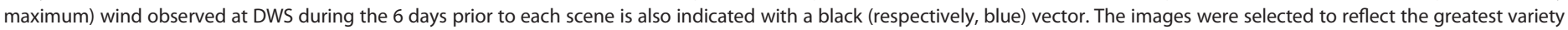
of states and patterns found in the archive. They are mainly discussed in section 3.4. Images in Figures $2 \mathrm{k}$ and $2 \mathrm{l}$ are taken $\sim 12 \mathrm{~h}$ apart and illustrate changes associated with diurnal warming. The color scale in Celsius for Figure $2 \mathrm{~h}$ has been shifted and corresponds to the one used for the months of October to December in Figure 3.

found important as well to explain these fine scales [e.g., Koračin et al., 2004]. Presumably as a result of low orography and thus limited local wind effects in the Cape Verde vicinity (as corroborated by an analysis presented in Appendix A), we demonstrate that a robust statistical relationship exists between the wind at the weather station and winds over the broader SSUC area which allows us to mainly rely on the former.

SST images are analyzed and used to make inferences about internal ocean dynamics (mainly upwelling and mixing). We recognize that SST patterns are also being shaped by ocean-atmosphere interactions. On the other hand, ocean-atmosphere heat exchanges should damp out SST contrasts and SSUC climatological winds are spatially smooth. Averaging over many different SST images, we therefore expect that the SST contrasts we identify primarily reflect advective and diffusive ocean processes. An important focus will be on SST minima because they are generally a reliable indicator of upwelling location. We further elaborate on this at the end of the manuscript.

Section 2 describes our wind and SST data. It also assesses the representativity of DWS wind data for winds over the entire SSUC. The results section (section 3 ) is then organized in sections that focus on a particular 


\section{QAGU Journal of Geophysical Research: Oceans}
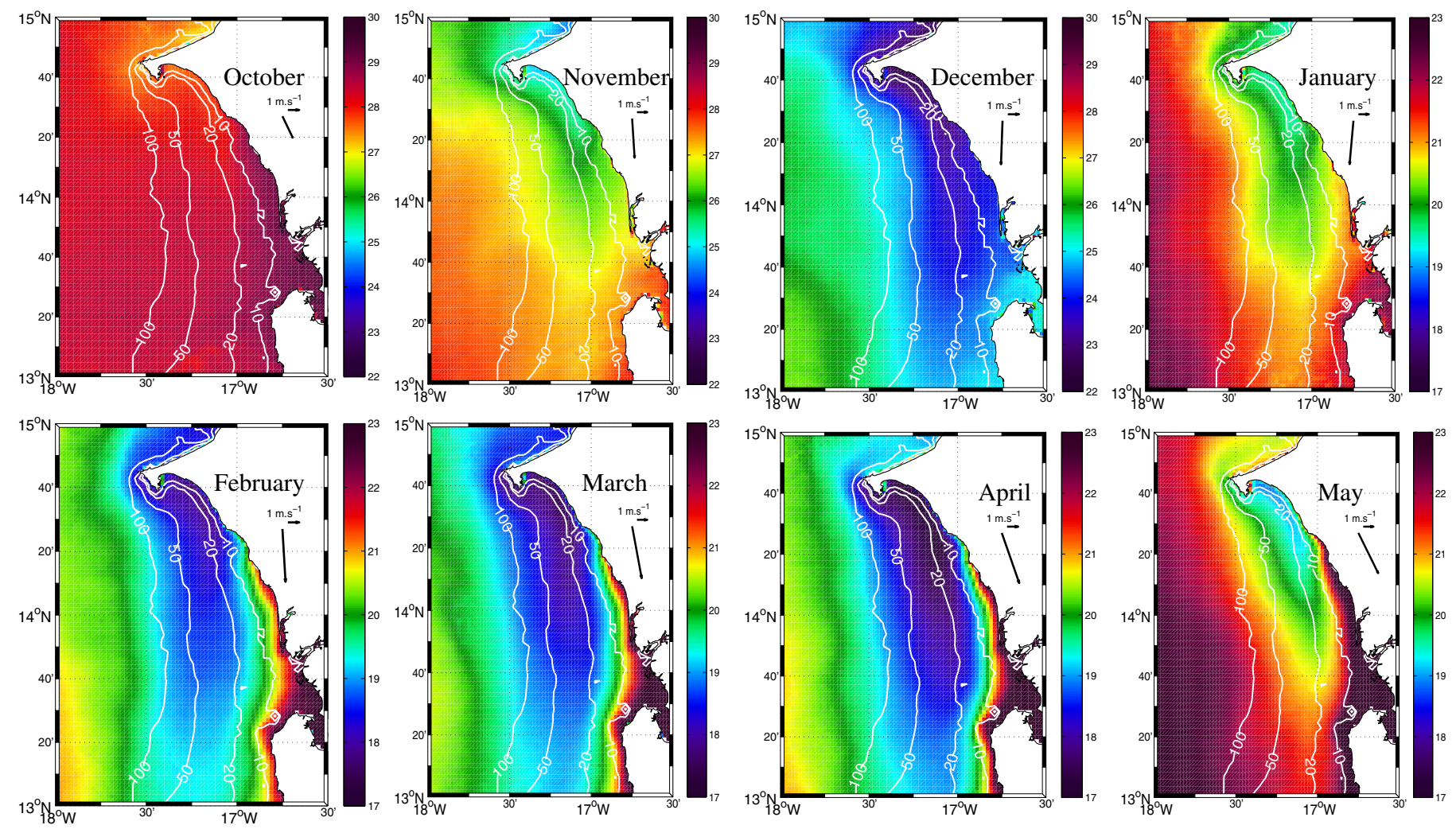

Figure 3. Monthly mean SST climatologies constructed using all available SST images over the study period (1 October 2005 to 30 May 2012 ). Note the two different color scales used

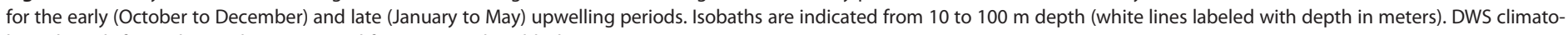
logical winds for each month are repeated from Figure $4 \mathrm{~b}$ as black vectors.

time scale: seasonal climatological cycle (section 3.1), intraseasonal/synoptic variability (section 3.2), and diurnal cycle (section 3.3). Intrinsic variability and the broader range of observed SSUC states are exposed in section 3.4. Interannual variability will be discussed in a separate study. Based on the identification of (mostly) recurrent SST patterns, we make inferences on the SSUC dynamical functioning in the final section. We also elaborate on the reasons why these recurrent patterns may be so pervasive in the SSUC.

\section{Material and Methods}

\subsection{Wind Data}

Global winds at the sea surface have been available for over a decade (September 1999 to November 2009), thanks to the QuikSCAT scatterometer which was onboard the Seawinds satellite. Level 2 QuikSCAT wind fields are available for the SSUC except over the scatterometer blind zone that extends $25-30 \mathrm{~km}$ from the shore (see Appendix A). We use the $12.5 \mathrm{~km}$ horizontal resolution product downloaded from podaac-ftp.jpl.nasa.gov/allData/quikscat/L2B12/v2/. Zero to two swaths per day cross the SSUC domain. Whenever the coverage is good enough, QuikSCAT winds are averaged over the area located between $13^{\circ} 30^{\prime} \mathrm{N}$ and $14^{\circ} 30^{\prime} \mathrm{N}$ of latitude and $17^{\circ} 30^{\prime} \mathrm{W}$ and $17^{\circ} \mathrm{W}$ of longitude to provide a SSUC wide-wind measurement $\mathbf{V}^{Q K}$. Because BWS winds (measured at Banjul, Gambia; $13^{\circ} 21^{\prime} \mathrm{N}, 16^{\circ} 48^{\prime} \mathrm{W}, 36 \mathrm{~m}$ above ground) tend to have important gaps and also tend to underestimate wind intensity over the SSUC (presumably due to important site effects, see section 3.3) we primarily rely on DWS for in situ wind measurements. DWS wind observations $\left(\mathbf{V}^{D S}\right)$ are taken at Dakar airport in Yoff located at $14^{\circ} 44^{\prime} \mathrm{N}, 17^{\circ} 30^{\prime} \mathrm{W}, 27 \mathrm{~m}$ above ground. The typical sampling interval is $30 \mathrm{~min}$. We could only access DWS winds from 2005 onward which restricts our study period to October 2005 to June 2012 (seven upwelling seasons).

The extent to which DWS winds are representative of wind conditions over the entire SSUC is estimated by comparing $\mathbf{V}^{Q K}$ and the time series of DWS winds subsampled the times where QuikSCAT measurements were done (precisely, $1 \mathrm{~h}$ averaging over a time interval centered on each QuikSCAT measurement). No 


\section{QAGU Journal of Geophysical Research: Oceans}
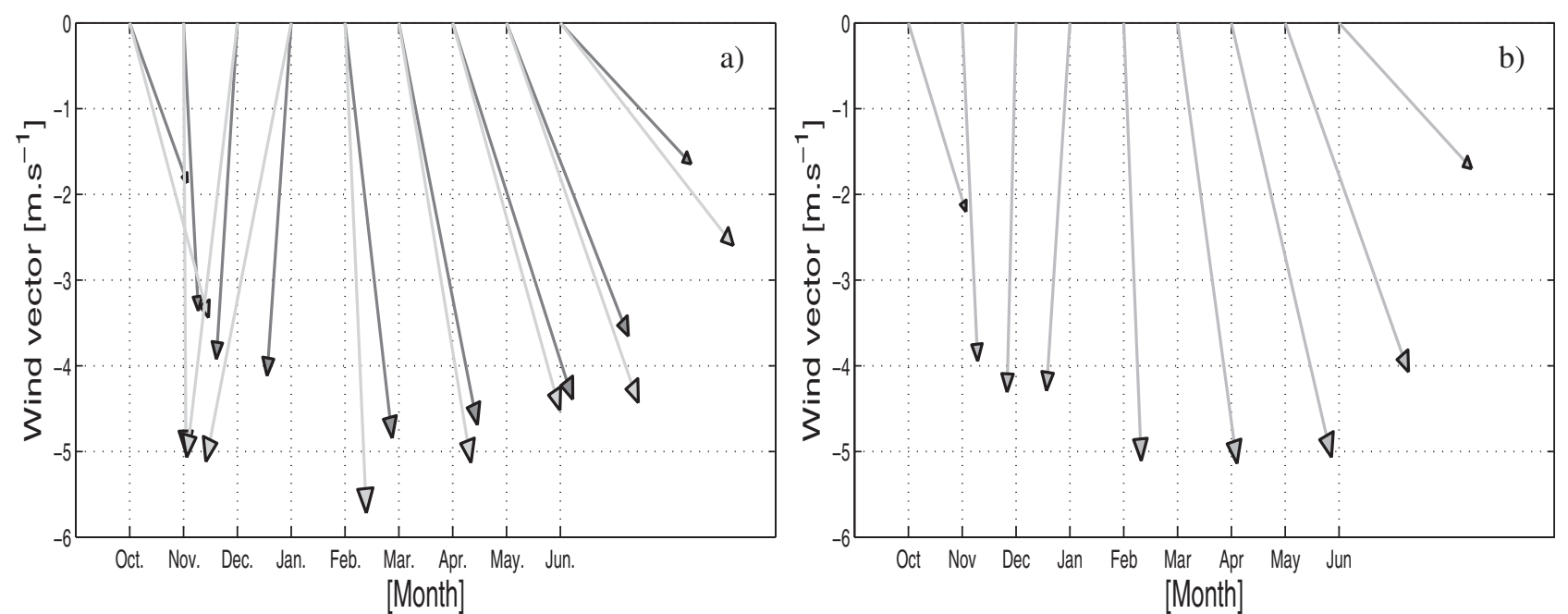

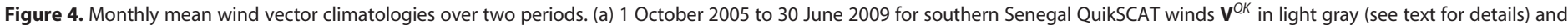
Dakar-Yoff weather station (V $\mathbf{V}^{D S}$ in dark gray). (b) 1 October 2005 to 30 June 2012 (our entire study period) for winds at Dakar-Yoff weather station (V $\mathbf{V}^{D S}$ in dark gray).

attempt was made to correct for the difference in elevation because this is only one in many potential biases. The wind comparison period is 2005-2009 when both DWS and QuikSCAT data are available.

Figure 4 shows both wind climatological cycles for October 2005 to June 2009 (as well as the DWS cycle for the entire study period October 2005 to June 2012, Figure 4b). Overall, both wind cycles are in agreement with previous estimates [Roy, 1989]. Both winds exhibit a similar seasonal cycle with a steady increase of upwelling favorable winds from October to February, a peak intensity in February-April $\left(\sim 5 \mathrm{~m} \mathrm{~s}^{-1}\right)$ and a general counterclockwise rotation as the upwelling season progresses (wind backing). A systematic orientation difference of $\sim 5^{\circ}-10^{\circ}$ with $\mathbf{V}^{D S}$ more to the east is also noticeable. Excluding the first and last months when upwelling conditions are erratic and differences are larger, winds derived from QuikSCAT are only 5$20 \%$ stronger than measured at DWS. The smallest differences are in March and April $\left(0.2 \mathrm{~m} \mathrm{~s}^{-1}\right.$ in March, $0.05 \mathrm{~m} \mathrm{~s}^{-1}$ in April). More generally, differences tend to diminish as the wind rotates from easterlies to westerlies. Note that much larger discrepancies are found when comparing DWS winds to QuikSCAT winds over northern Senegal (averaging between $14^{\circ} 45^{\prime} \mathrm{N}$ and $16^{\circ} 05^{\prime} \mathrm{N}$ ) than over the SSUC (not shown).

To further quantify QuikSCAT-DWS wind differences, one to one comparison of their zonal $(\mathrm{u})$ and meridional (v) components is presented in Figure 5. Both components are highly correlated ( 0.78 for $u$ and 0.74 for v). The associated regressions for the zonal and meridional component are, respectively, $u^{Q K}=1.3 u^{D S}-0.5$ and $v^{Q K}=0.85 v^{D S}-1.5$ (in $\mathrm{m} \mathrm{s}^{-1}$ ). We note that strong easterly winds are under-represented at DWS (large deviations for large negative $\left.u^{Q K}\right)$.

The good correspondence found between winds at Yoff and winds over the SSUC reflects their strong correlation on synoptic, seasonal and longer time scales. In Appendix A, we present the climatological QuiKSCAT wind field for the February-April period computed by following a procedure designed to minimize the blind zone. Despite partial coverage in our region of interest this analysis confirms the limited importance of local wind effects. Keeping in mind a tendency of DWS winds to misrepresent occasional strong easterlies over the SSUC our results provide good support for using DWS wind data as SSUC winds proxy. We will do so, except when studying the SST diurnal cycle whose understanding a priori requires local wind information at scales finer than we presently have. The diurnal cycle of nearshore winds is known to be strongly dependent on exact location [Woodson et al., 2007] and it cannot be captured using QuikSCAT winds which are available at most twice per day. Pending in situ measurements with marine weather buoys a preliminary exploration in the SSUC will consist in comparing wind diurnal cycles at two weather stations (Dakar and Banjul) over limited time periods when in situ R/V atmospheric data are also available in the SSUC region (section 3.3).

\subsection{Spatial Sea Surface Temperature}

Despite their excellent coverage, it is not possible to use microwave SSTs (and products that heavily rely on them such as OSTIA [Donlon et al., 2012]) because their resolution is insufficient to capture the SSUC 


\section{QAGU Journal of Geophysical Research: Oceans}
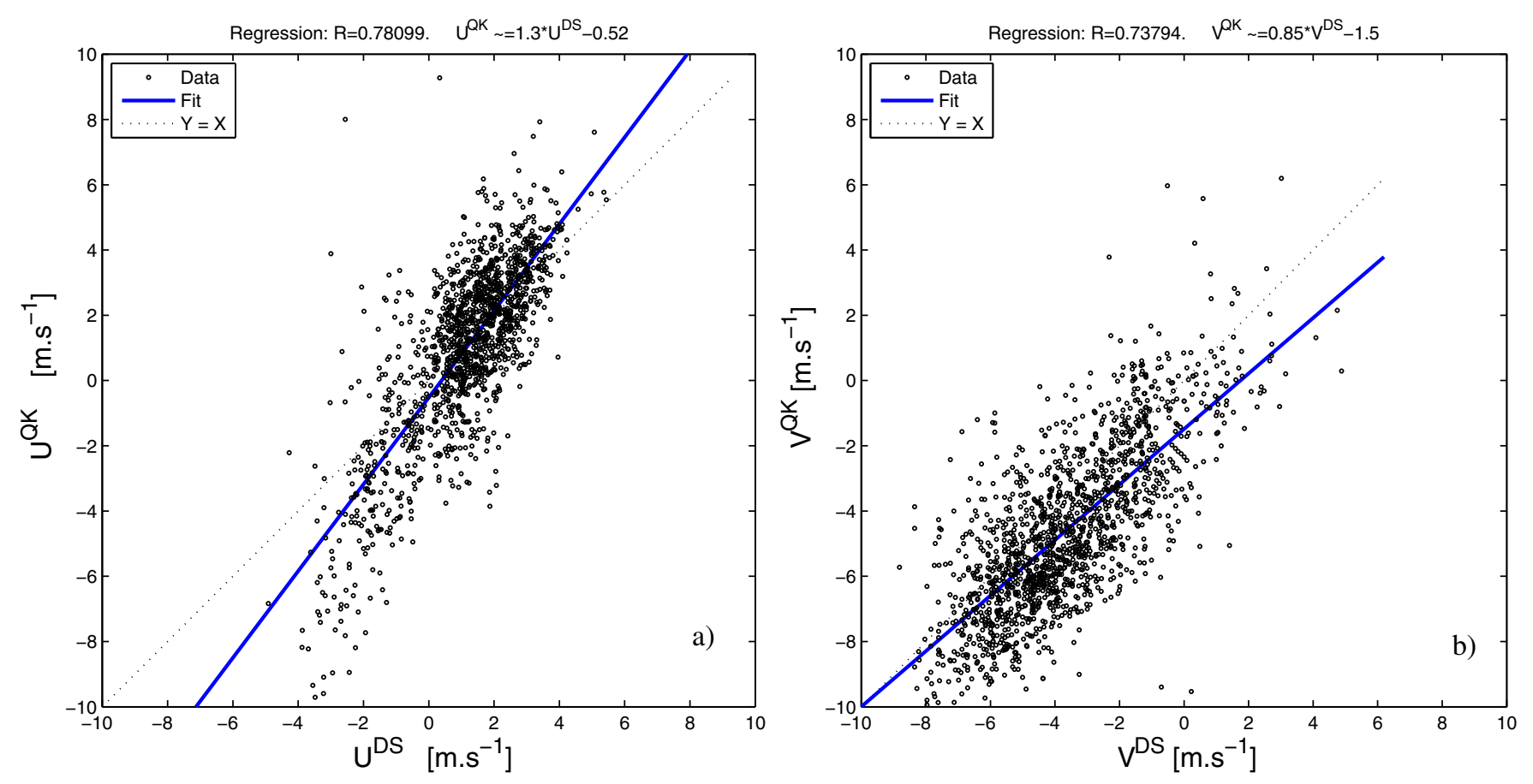

Figure 5. Scatterplots between the (left) meridional and (right) zonal components of southern Senegal Quikscat and Dakar-Yoff weather station winds. DWS winds have been subsampled at the QuikSCAT measurement times (see text for details). The worst agreement corresponds to intense easterly QuikSCAT winds.

patterns we are interested in, e.g., warm inshore water and midshelf SST minimum south of $14^{\circ} 30^{\prime} \mathrm{N}$. Instead, we rely on MODIS and SEVIRI SST data.

The Moderate Resolution Imaging Spectroradiometer (MODIS) was launched aboard the Terra satellite on 18 December 1999 (10:30 A.M. equator crossing time, descending) and the Aqua satellite on 4 May 2002 (1:30 P.M. equator crossing time, ascending) for global monitoring of the atmosphere, terrestrial ecosystems, and oceans provide kilometer-scale SST information with almost complete global coverage in 1 day [Savtchenko et al., 2004].

We use Level 2 data in swath geometry downloaded from oceancolor.gsfc.nasa.gov for the period October 2005 to May 2012. Algorithms to flag data for cloud contamination tend to be overly conservative in upwelling areas. Typical SST gradients of $\sim 1^{\circ} \mathrm{km}^{-1}$ or more are often considered as a signature of cloud, which leads to significant reduction of good pixels over areas that are particularly interesting in this study. The practical way we found to deal with this was to carefully screen every individual MODIS scene for abnormal patterns or values in SST (see Nieto et al. [2012], for an alternative more elaborate procedure). Regions with SST lower than $15^{\circ}$ or suspect SST patterns were discarded. Images with more than $10 \%$ of the SSUC domain covered with discarded pixels were removed from the analysis. In addition, images in the visible for daytime scenes were examined for the presence of aerosols or thin cloud cover. Of the entire MODIS archive, for our period of interest, 1604 images are used in the analyses, $42 \%$ of which correspond to nighttime. March, April, and February have the largest number of images (respectively, 307, 254, and 253) and October has by far the smallest (85 images; see Figure 6).

To facilitate averaging over hundreds of images with different pixel sizes and locations, the SST data were regridded on a regular 2 by $2 \mathrm{~km}$ grid.

To investigate SST diurnal fluctuations (section 3.3), we use hourly SST fields produced operationally from the Spinning Enhanced Visible and Infra-Red Imager (SEVIRI) onboard Meteosat Second Generation (MSG) since the 2 February 2011 by the European Organisation for the Exploitation of Meteorological Satellites (EUMETSAT) at Météo-France [Le Borgne et al., 2011]. Their spatial resolution is approximately $5.5 \mathrm{~km}$. The SEVIRI data are provided with six-level quality flags ranging from no data to best quality. We use the data with quality flag 3 or above as recommended. 


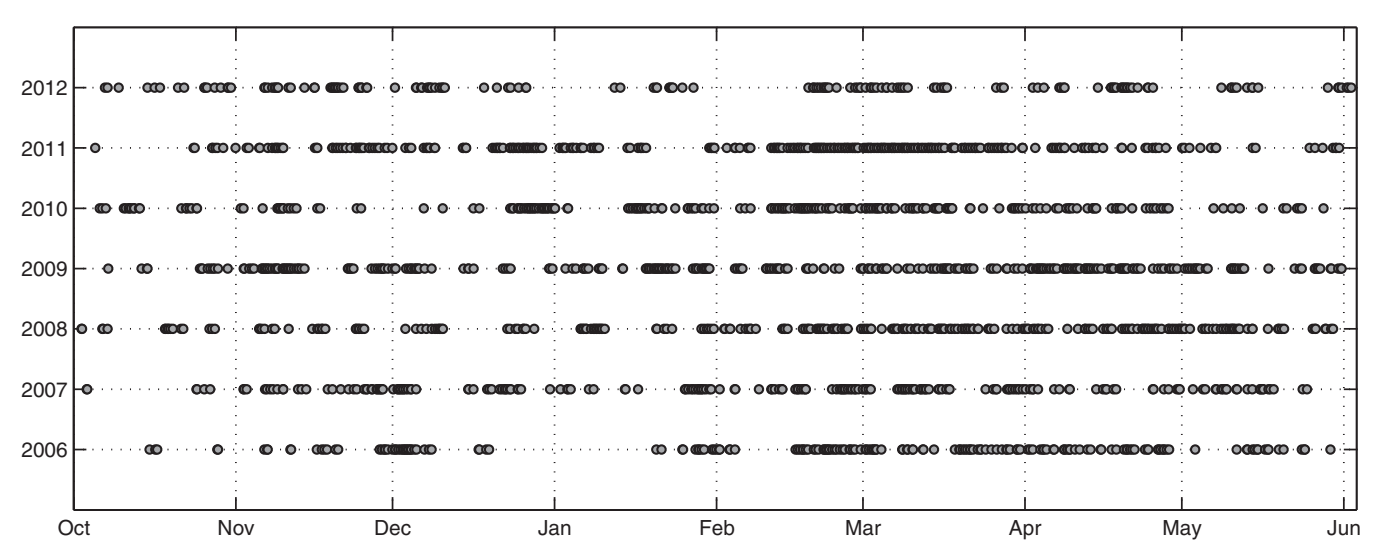

Figure 6. Timeline for the study period indicating the dates for which SST images with near-zero cloud/aerosol masking were found (gray dots).

Because we are particularly interested in the period February-March during which cloud contamination is least important and observations programs have recently taken place we only compute monthly mean diurnal cycles for February to March 2012 and 2013. The analysis will be extended when a longer time series is available.

\section{Results}

Being particularly interested in the identification of recurrent SSUC states and patterns (and their underlying dynamics) on scales of hundred of kilometers and less, we start by presenting climatological SST analyses that help to describe these states. In doing so, we leave aside more intermittent and complex features some of which will be discussed in section 3.4.

\subsection{SSUC Seasonal Pattern}

Thanks to the high resolution of MODIS images and careful screening for cloud and aerosol contamination, monthly SST fields at unprecedented resolution are obtained and presented in Figure 3, for the period October to May. The upwelling signal is hardly perceptible in October with only a $\sim 1^{\circ} \mathrm{C}$ temperature decrease in the immediate vicinity of Cape Verde. The general pattern visible from November onward is that previously described in, e.g., Roy [1998]: lowest temperatures in the northern part of the SSUC, i.e., the Hann Bight; a temperature minimum well separated from the shore over most of the upwelling season just south of Cape Gombaru ( $14^{\circ} 29^{\prime} \mathrm{N}$ see Figure $2 \mathrm{a}$; the change in coastline orientation around the cape is presumably instrumental in the detachment); a temperature increase of several degrees Celsius both in the nearshore and offshore direction except in the beginning of the season (October-November). The temperature contrast at the coastal front reaches about $4^{\circ} \mathrm{C}$ over $30-40 \mathrm{~km}$ from February to May whereas it is only $1.5^{\circ} \mathrm{C}$ over $35 \mathrm{~km}$ in January and insignificant the rest of the season. The offshore temperature contrast exhibits less temporal variations and is also less intense, of the order of $2^{\circ} \mathrm{C}$ over $100 \mathrm{~km}$ from December to May.

The core of the upwelling season occurs from February to April, a 3 month period during which SST exhibits very limited changes. Conversely, important transitions in SST take place between January and February, and also between April and May. These transitions are not associated with major changes in meridional wind intensity ( $v^{D S}$ or $v^{Q K}$ ) which increases or decreases by about $10-20 \%$ over these periods (Figures $4 a$ and $4 \mathrm{~b}$ ). Comparing meridional wind intensity between May and the February-April period over the entire SSUC domain (using the QuikSCAT product described in Appendix A), we find that upwelling winds drop significantly more in the southern part of the SSUC ( $35 \%$ around $12^{\circ} 30^{\prime} \mathrm{N}$ ) than offshore off Cape Verde $(10 \%)$ or in the vicinity of $14^{\circ} \mathrm{N}, 17^{\circ} 15^{\prime} \mathrm{W}$ (the reduction of $v^{\mathrm{QK}}$ is $17 \%$ ). This suggests that remotely forced upwelling effects [Pringle and Riser, 2003] modulated by the seasonal migration of the ITCZ are important in (at least) the late phase of the SSUC upwelling. No such explanation helps to understand the JanuaryFebruary transition for which we simply note that it is associated with the most significant month-to-month $\mathbf{V}^{\mathrm{QK}}$ direction shift (Figure 4a). 


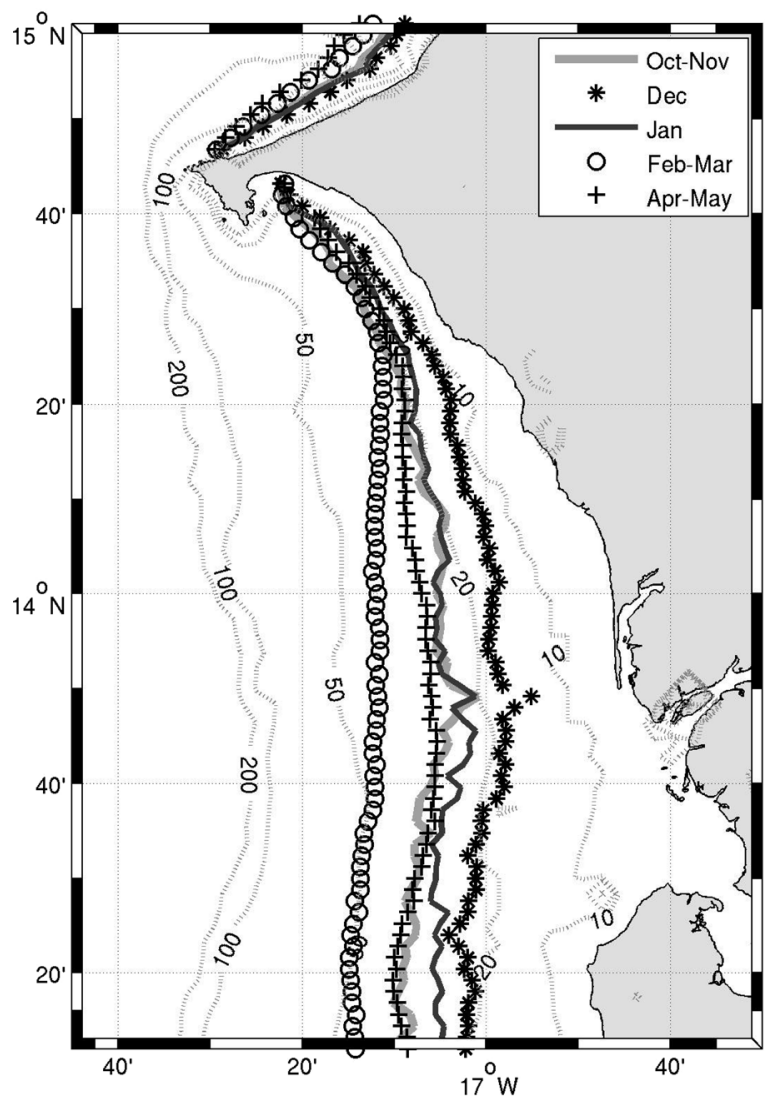

Figure 7. Monthly/bimonthly mean position of the zonal SST minima as a function of latitude. Consecutive months with SST minima too close to be distinguished are presented as one (February-March and April-May). Bathymetry is also shown with dotted lines (isobaths 10, 20, 50, 100, and $200 \mathrm{~m}$ ).
As it allows one to locate where the upwelling signal is the most intense, the zonal position of the SST minima is an important quantity [Benazzouz et al., 2014]. It is shown in Figure 7 as monthly averages throughout the upwelling season (October-May). Note that the averaging involves all SST minima identified for nighttime images only. We do so because SST and its local minima can be affected by diurnal warming (see section 3.3) with limited vertical extension (on the scale of a meter or less) that mask the interior upwelling dynamics. The monthly averaged location of zonal SST minima plotted as a function of latitude forms smooth lines that undergo an offshore displacement from December to February-March before retreating inshore somewhat in April-May. The amplitude of this seasonal displacement increases sharply south of Cape Gombaru and reaches about $30 \mathrm{~km}$ south of $14^{\circ} 10^{\prime} \mathrm{N}$ where the SST minima move from the 15 to $20 \mathrm{~m}$ isobath in December to the 40-50 m isobath in FebruaryMarch. The mean position of the SST minima and their seasonal displacement are in broad agreement with theoretical expectations drawn from Estrade et al. [2008] given the wind climatological

cycle (Figure 4b): wind increase from November to February translates into offshore migration of the SST minimum and vice versa toward the end of the upwelling season. A notable exception occurs in October and November whose SST minima lie further offshore than those of December despite weaker winds, particularly compared with October. Likewise, the location of the May SST minima being offshore of that for December and to a lesser extent January cannot be explained by wind differences (see Figure 4b).

A finer analysis sheds light on the apparent anomalous behavior for October-November. In Figure 8, we show the probability density function (PDF) of having the SST minimum located at some longitude, computed over latitude bands of $2 \mathrm{~km}$ from $13^{\circ} 15^{\prime} \mathrm{N}$ to $15^{\circ} \mathrm{N}$. The SST minima during the early upwelling season (October and to a lesser extent November) exhibit considerable scatter compared to the period of established upwelling (December-April). We attribute this to the weakness of the upwelling signal in OctoberNovember, whose impact on SST is more easily overshadowed by isolated offshore SST minima generated by other processes (see section 4). The examination of individual SST images for the October-November period confirms this explanation by revealing numerous pixels scattered over the outer shelf and slope regions with temperature as cold or slightly colder than those in the weakly active coastal upwelling.

More importantly, Figure 8 reveals a bimodal distribution of the SST minima south of $14^{\circ} 30^{\prime} \mathrm{N}$, from November to January. A coastal minimum is located inshore of the $10 \mathrm{~m}$ isobath. The only possible source of coastal cooling involves the advection of subsurface water that maintains enough of its cold signature while approaching the shore. This demonstrates that upwelling remains important within kilometers from the coast during that period. Inspecting SST images individually, we find many instances where both the coastal and the offshore cool water signal are simultaneously present over a wide latitude band (e.g., see Figure $2 \mathrm{~h}$ ). From February onward, the SST minima are generally found offshore over a $\sim 50 \mathrm{~km}$ region. Rare occurrences of nearshore SST minimum can still be found but the band inshore of roughly $17^{\circ} \mathrm{W}$ is predominantly occupied by waters that are several degrees warmer than the corresponding minimum SST at the same latitude. 


\section{QAGU Journal of Geophysical Research: Oceans}
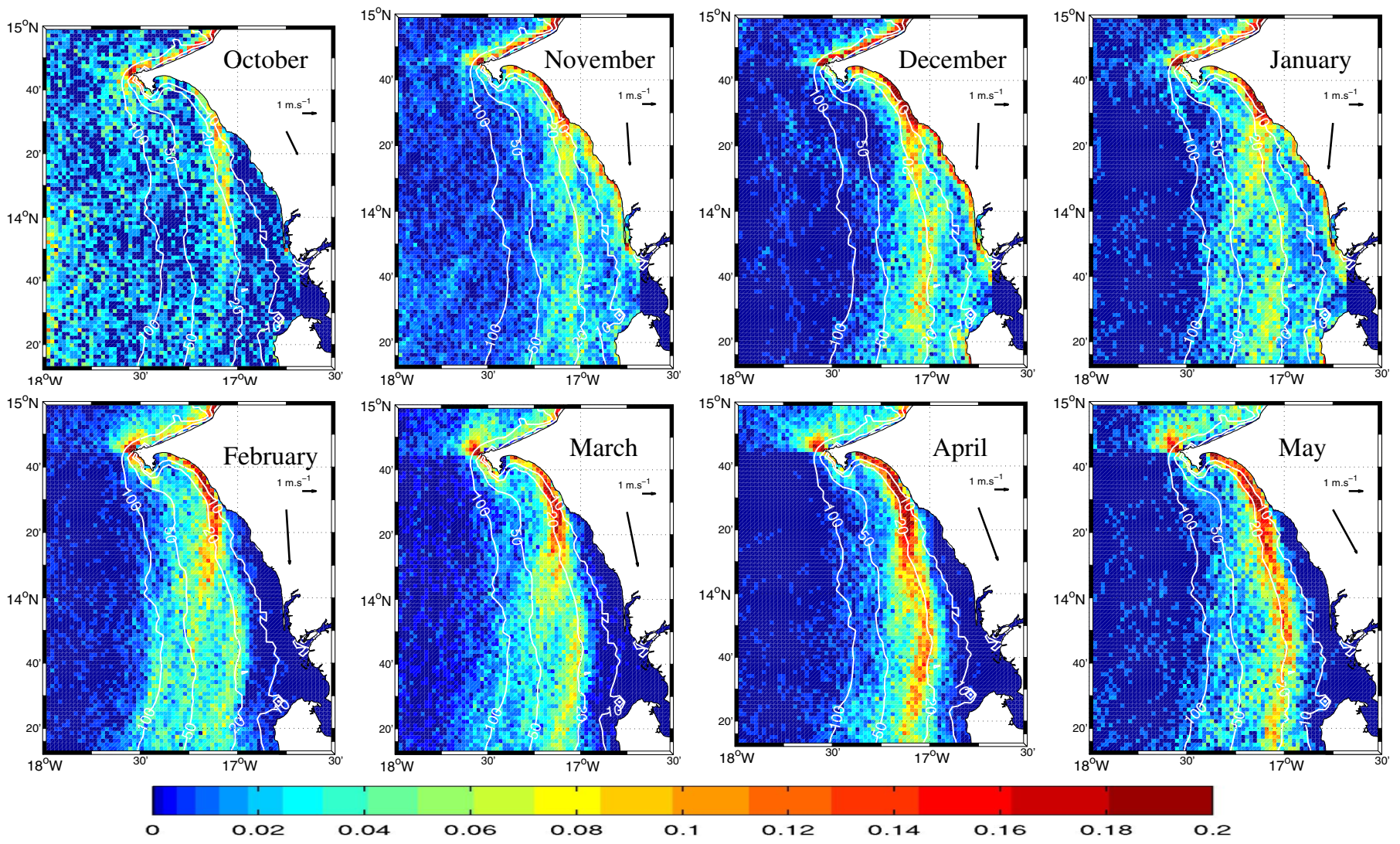

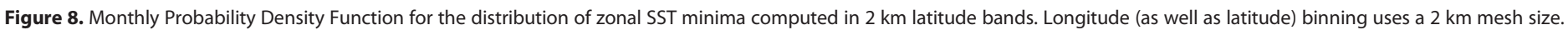
Note that the color scale is nonlinear. Isobath 10, 20, 50, and $100 \mathrm{~m}$ are shown as white lines. DWS climatological winds for each month are repeated from Figure $4 \mathrm{~b}$ as black vectors.

Close inspection of Figure 8 reveals other aspects of the SSUC dynamics that have not been previously noted to our knowledge. First, high values of the monthly Probability Density Function (PDF) follow elongated patterns separated by lower values. In February-April, a northern branch with a comma shape goes from the Hann Bight down to about $14^{\circ} \mathrm{N}, 17^{\circ} 15^{\prime} \mathrm{W}$. A second branch located at about $17^{\circ} \mathrm{W}$ south of $14^{\circ} \mathrm{N}$ can also be seen. The separation between them is subtle particularly in April but it can be seen during all 3 months which rules out statistical uncertainty (note that such features also seem consistent with instantaneous SST images in Figures $2 \mathrm{i}$ and $2 \mathrm{~g}$ ). Also, plots for February and to a lesser extent March indicate that, south of $14^{\circ} \mathrm{N}$, the PDF for SST minima is slightly more elevated along a segment that follows the $100 \mathrm{~m}$ isobath (i.e., the shelf break) than the shelf background values. These patterns are discussed further below.

From February to May, the wind orientation is north-northwesterly, i.e., it is favorable to local upwelling along the Cape Verde headland. Waters offshore of the headland is slightly colder than in the northern domain during this period (Figure 3) which supports the presence of a local Cape Verde upwelling (as opposed to southward advection of water upwelled in the north). The distribution of SST minima around $14^{\circ} 40^{\prime} \mathrm{N}-14^{\circ} 45^{\prime} \mathrm{N}$ is also consistent with this, with larger values of the PDF very close to shore. The signature of this local upwelling does not extend southward, at least in Figure 8 (SST minima are most frequently found at the coast in the Hann Bight south of $14^{\circ} 40^{\prime} \mathrm{N}$ ). On the other hand upwelling along the headland seems to impact the distribution of SST minima toward the north: a patch of high probability with a typical size $\sim 10-15 \mathrm{~km}$ seems to originate from the northern tip of Cape Verde headland and spread northward. This is in contrast to the roughly continuous line of large PDF values running along the shore of northern Senegal in December-January, when winds are more from the east and would thus be more favorable to coastal upwelling there. We relate this northern signature of the Cape Verde upwelling to the influence of the poleward flowing Mauritanian current [Peña-Izquierdo et al., 2012] that intensifies as it approaches the headland and bathymetry steepens considerably. A situation where the cold wake of water emanating from the Cape Verde upwelling may be advected northward (respectively, northwestward) by the Mauritanian current can be found in Figure $2 \mathrm{k}$ (respectively, Figure $2 \mathrm{~d}$ ). 

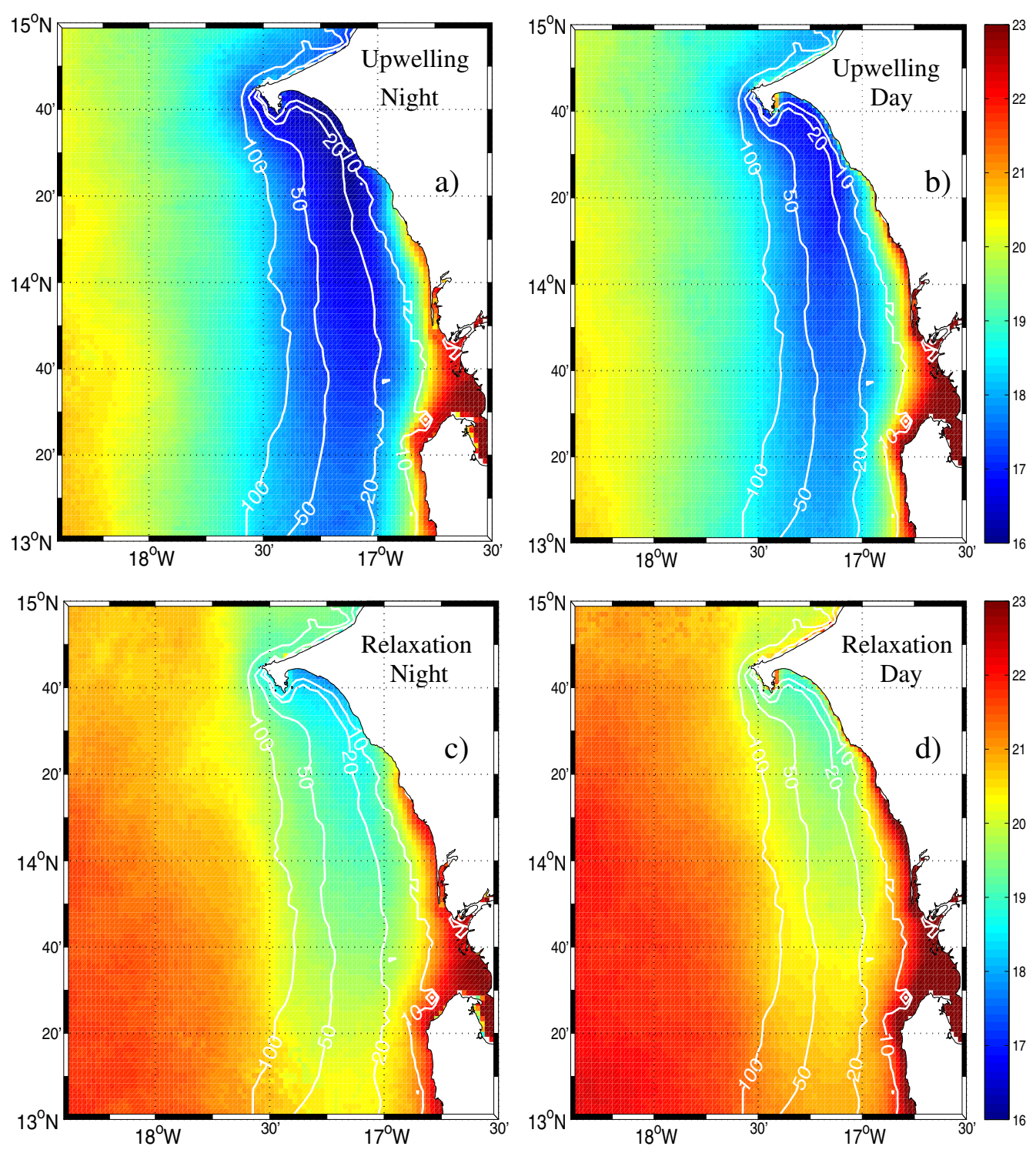

Figure 9. Composite average SST for (left) nighttime and (right) daytime clear-sky MODIS images during (top) upwelling events and (bottom) relaxation conditions, respectively, defined by 4 day averaged DWS winds being above (respectively, below) a threshold of $5.5 \mathrm{~m} \mathrm{~s} \mathrm{~s}^{-1}$ (respectively, $4 \mathrm{~m} \mathrm{~s}^{-1}$ ). Isobaths $10,20,50$, and $100 \mathrm{~m}$ are shown as white lines.

\subsection{Intraseasonal Variability: Upwelling Versus Relaxation Events}

As in other upwelling regions, the SSUC wind forcing is characterized by successions of upwelling events and relaxations with typical time scales of 3-10 days (not shown). Synoptic variability has important ecological implications in upwelling systems [Roughan et al., 2006] and this is also presumably the case in the SSUC. In Figure 9, composite averaging of MODIS nighttime SST for upwelling and relaxation conditions are presented. (Daytime composite is also shown and will be discussed in the next section.) We only consider the period February-April during which climatological winds do not change significantly. Upwelling event (respectively, relaxation event) conditions are defined by a mean meridional wind speed at DWS higher (respectively, lower) than $V_{u}=5.5 \mathrm{~m} \mathrm{~s}^{-1}$ (respectively, $V_{r}=4 \mathrm{~m} \mathrm{~s}^{-1}$ ) over a time interval $T_{a}=4$ days preceding the image scene. This 4 days (approximately two inertial period) averaging ensures that the system had time to adjust to the wind conditions.

Ninety five and sixty five images, respectively, form composites that are associated with an average meridional wind speed of $6.2 \mathrm{~m} \mathrm{~s}^{-1}$ (upwelling event) and $3.1 \mathrm{~m} \mathrm{~s}^{-1}$ (relaxation event). Mean upwelling and relaxation SST exhibit the same patterns and have no discernable qualitative difference. SST along SST minimum 


\section{QAGU Journal of Geophysical Research: Oceans}
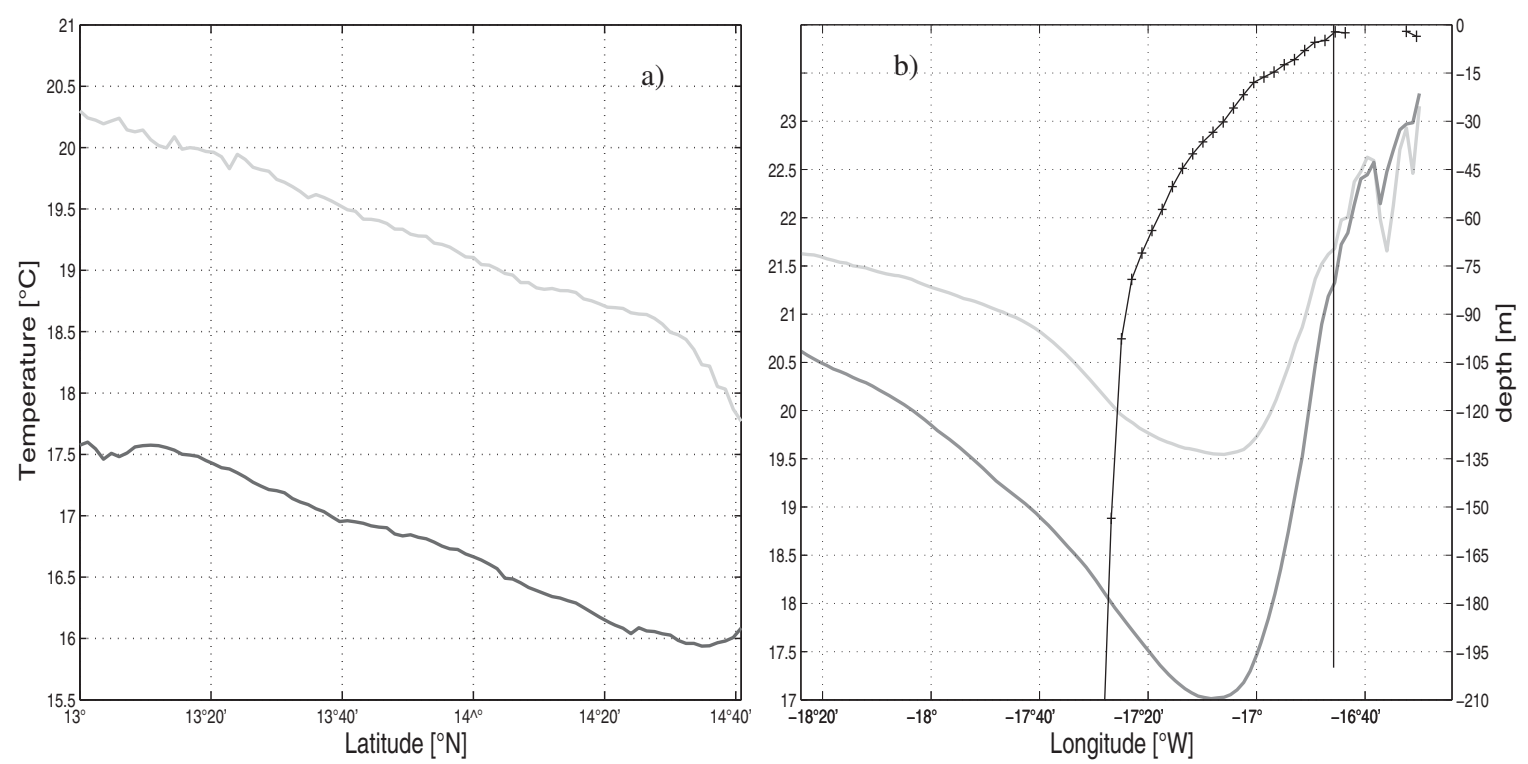

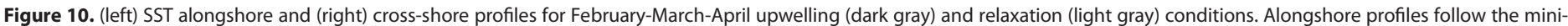
mum SST line found for each corresponding composite (Figures 9a and $9 \mathrm{c}$ ). Acrossshore profiles are obtained by averaging over the latitude band $13^{\circ} 40^{\prime} \mathrm{N}-14^{\circ} 15^{\prime} \mathrm{N}$. In (b), the average depth is indicated as a function of longitude (black solid line with markers, right axis) and the separation between the coastal ocean and estuarine system located east of Sangomar point is shown with a black vertical line.

lines (computed as in section 3.1) for the upwelling and relaxation situations differ by $2-2.5^{\circ} \mathrm{C}$ over most of the SSUC with a slight tendency to increase toward the south of the domain (from $1.8^{\circ} \mathrm{C}$ at Dakar to $2.7^{\circ} \mathrm{C}$ at $13^{\circ} \mathrm{N}$; see Figure $10 \mathrm{a}$ ). In both cases, SST increases regularly away from the upwelling center south of Cape Verde.

The SST cross-shore profiles averaged over the latitude band $13^{\circ} 40^{\prime} \mathrm{N}-14^{\circ} 15^{\prime} \mathrm{N}$, shown in Figure $10 \mathrm{~b}$, are more contrasted. The SST difference between upwelling and relaxation conditions reaches a little over $2.5^{\circ} \mathrm{C}$ over the central part of the shelf where upwelling takes place. It decreases rapidly over the outer shelf and slope region but remains around $1^{\circ} \mathrm{C}$ as far west as $19^{\circ} \mathrm{W}$. Time scales for upwelled water to travel from the upwelling region to $19^{\circ} \mathrm{W}$ at typical speeds of $0.2 \mathrm{~m} \mathrm{~s}^{-1}$ are of the order of 10 days. (The presence of filaments associated with stronger cross-shore currents [Meunier et al., 2012] may reduce this travel time for some water parcels but the longshore and time averaged cross-shore flow should be driven by Ekman dynamics, so $0.2 \mathrm{~m} \mathrm{~s}^{-1}$ is a reasonable upper bound.) This is somewhat longer than what most synoptic events last. Therefore, we suspect that the offshore $1^{\circ} \mathrm{C}$ difference is not due to cross-shore advection of the coastal upwelling signal but rather to local cooling processes, primarily changes in vertical mixing and entrainment in the surface boundary layer by wind turbulence. Air-sea fluxes probably also contribute to this difference as latent heat fluxes depend on wind speed; thus the intensification of the northerlies tends to advect cooler air over the region.

More importantly, we note that relaxation conditions lead to a broad region of SST minima whereas SST minima are more focused for the upwelling composite. To clarify this behavior, a relaxation/upwelling composite PDF of SST minimum (similar to Figure 8) is done for February-April with the same 4 and $5.5 \mathrm{~m} \mathrm{~s}^{-1}$ thresholds used before. SST minima in upwelling conditions are sharply distributed between the 20 and $50 \mathrm{~m}$ isobaths (see Figure 11), i.e., in a way that is consistent with upwelling taking place off the inner shelf. The same two comma-like patterns found in Figure 8 stand out even more clearly. In contrast, SST minima for relaxation conditions are scattered quite uniformly over the entire mid/outer shelf except for slightly higher PDF values about the $20 \mathrm{~m}$ and, south of $14^{\circ} \mathrm{N}, 100 \mathrm{~m}$ isobaths. The latter reveals enhanced surface cooling at the shelf break, as found over many nonupwelling shelf breaks in association with internal gravity wave/tide breaking [Sharples et al., 2007]. Over the northern part of the shelf increased scattering of SST minima is also observed for relaxation conditions, although not as far as the shelf break. A possible explanation would be that stronger winds in the northern SSUC maintain coastal SST during relaxations that are too cold to let shelf break cooling through internal wave breaking emerge from the analysis. 


\section{QAGU Journal of Geophysical Research: Oceans}
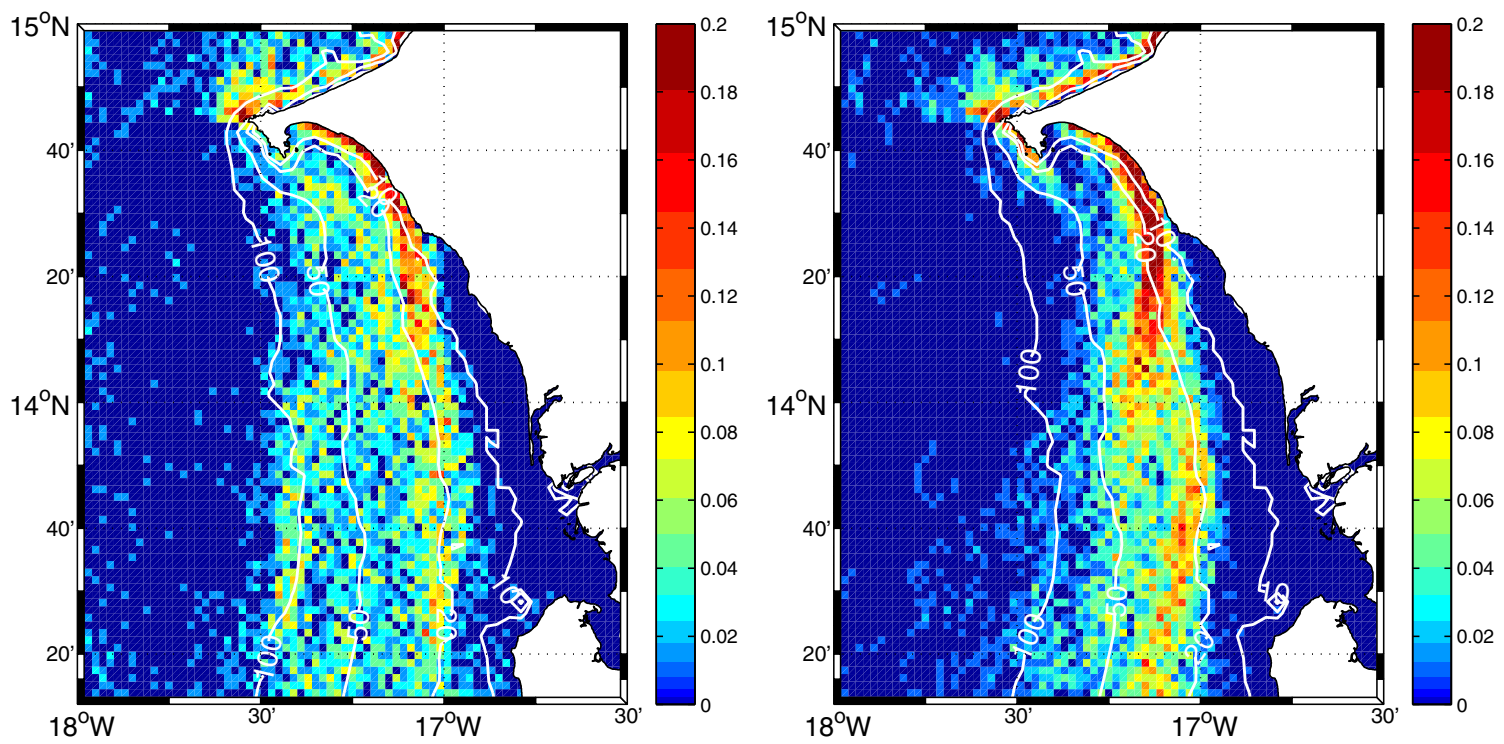

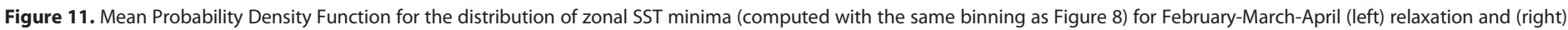
upwelling event conditions, respectively, defined by 4 day averaged DWS winds being below (respectively, above) a threshold of $4 \mathrm{~m} \mathrm{~s}^{-1}$ (respectively, $5.5 \mathrm{~m} \mathrm{~s}^{-1}$ ).

Inshore of the minimum SST zone the upwelling/relaxation SST difference seen in Figure 11 decreases rapidly and it is $\sim 0$ over the estuarine region east of Sangomar point (see location in Figure 2). From this we confirm that, in late winter-early spring, upwelling dynamics exert an increasingly limited influence as one approaches shore. Note though that the offshore half of the warm coastal strip is affected by upwelling conditions, with cooling $\approx 1^{\circ} \mathrm{C}$ at the $10 \mathrm{~m}$ isobath. Hydrological measurements carried out in March 2013 south of $14^{\circ} 20^{\circ} \mathrm{N}$ during moderate upwelling conditions do not show signs of cold bottom water being advected inshore of the $20 \mathrm{~m}$ isobath (X. Capet et al., manuscript in preparation, 2015). This would indicate that lateral mixing and perhaps air-sea fluxes are responsible for the cooling found in the longitude range $16^{\circ} 50^{\prime}-17^{\circ} \mathrm{W}$ during sustained upwelling conditions.

Obviously, our results depend on the values we choose for relaxation/upwelling wind intensity thresholds $\left(V_{u}, V_{r}\right)$ and also to a lesser extent, the averaging time interval of $T_{a}$. Using more extreme criteria to separate upwelling and relaxation conditions as well as increasing $T_{a}$ leads to more marked differences (e.g., major erosions of the inner-shelf warm strip can occur during strong upwelling events; see Figures $2 b, 2 f$, and $2 \mathrm{i}$ ). On the other hand, large $T_{a}$ pose statistical significance issues given the weakness of the wind synoptic variability. Indeed, we find that daily averaged alongshore winds at DWS for February-March-April 2006-2012 are $65 \%$ (respectively, $85 \%$ ) of the time between 3.2 and $5.8 \mathrm{~m} \mathrm{~s}^{-1}$ (respectively, 2.2 and $6.8 \mathrm{~m} \mathrm{~s}^{-1}$ ). We also find only six occurrences of daily wind reversals (southerly winds) whose intensity never exceeds $1.8 \mathrm{~m} \mathrm{~s}^{-1}$.

Figure 9 suggests that the SSUC does not, on average, respond dramatically to the wind synoptic perturbations, which should at least in part be attributed to the limited amplitude of these perturbations. This does not preclude more subtle circulation changes that are not captured here because of the averaging procedure, or because they would have no clear signature on SST (e.g., a reversal of inner-shelf meridional currents). Nevertheless, this analysis reinforces the idea that the SSUC functioning differs from those of other upwelling centers where relaxation phases correspond to major physical and ecological system disruptions [Roughan et al., 2006; Lamb and Peterson, 2005; Graham and Largier, 1997], e.g., with reorganizations of SST patterns and, more importantly, retention/dispersion structures.

\subsection{The SSUC Diurnal Cycle}

Midday MODIS SST images (taken between 11 A.M. and 4 P.M.) reveal heterogeneous diurnal warming over the SSUC. They often exhibit a much greater complexity (compare Figures $2 \mathrm{k}$ and $2 \mathrm{l}$ taken $12 \mathrm{~h}$ apart) and day-to-day variability than nighttime images. Indications of diurnal effects in SST also manifest in the upwelling/relaxation composites for the day images (computed as nighttime composites in section 3.2) shown in Figure 9. More precisely, the compositing reveals that diurnal temperatures over the shelf are 
significantly warmer $\left(\sim 1^{\circ}\right)$, especially during relaxation conditions. Off the shelf and/or during upwelling conditions (i.e., in conditions where air-sea fluxes are less favorable to the formation of a thin warm surface layer) diurnal warming is much less intense.

To shed light into the SSUC diurnal cycle, we start by describing the wind and SST daily cycles for 4 periods of 1 month (February-March 2012 and 2013). For these periods, we have access to hourly MSG SST images that we project on a regular grid (section 2) to construct hourly time series of SST at every pixel. Gaps due to cloud/aerosols contamination that are shorter than $3 \mathrm{~h}$ are filled by linear interpolation. Longer gaps are not filled. A mean daily cycle is then constructed at every pixel for each of the 4 months. Likewise, daily wind cycles at DWS are formed by averaging all observations for each month.

Figure 12 represents the peak to peak value (twice the amplitude) of the mean daily cycle as a function of position in the SSUC. Pixels with less than $70 \%$ good SST observations are blanked out. The signature of the diurnal cycle is present over the inner and midshelf but the patterns and magnitudes differ between months. The largest monthly averaged diurnal cycle magnitudes are obtained in March 2012 and February $2013\left(2^{\circ}\right.$ or more). During these two periods, occasional $8^{\circ} \mathrm{C}$ day-night differences are found while $5^{\circ}$ differences are common in waters 20-40 m deep.

Smaller monthly averaged day-night differences ( $1^{\circ}$ or less over the shelf) correspond to February 2012 and March 2013. Offshore the cycle, amplitude is strongly reduced to $50 \%$ or less of the nearshore values. Except for a few outliers maximum daily SST is reached in the afternoon (between 3 and 6 P.M.) everywhere in the domain, with the earliest maxima (3-4 P.M.) being concentrated in the nearshore region (not shown) where the SST cycle amplitude is largest. SST minima are reached between 6 and 9 A.M. with no clear pattern in the spatial distribution of the exact timings (not shown). To help visualize how SST can be modified by diurnal warming on time scales of hours we show Figures $2 \mathrm{k}$ and $2 \mathrm{l}$ taken $\sim 12 \mathrm{~h}$ apart during a moderate to strong upwelling event. SST differences reaching over $5^{\circ}$ can be found in the northern part of the SSUC. The upwelling signal in SST is barely visible in the afternoon throughout the domain.

Diurnal SST fluctuations depend on several factors that are mutually interdependent [Gentemann et al., 2009; Merchant et al., 2008]: wind intensity including its diurnal cycle, insolation, nonsolar air-sea heat fluxes (modulated by SST patterns and atmospheric conditions on a wide range of scales), subsurface stratification and shear, and light penetration (and hence near-surface plankton concentration and turbidity ...).

Understanding the processes responsible for the patterns shown in Figure 12 would require an extensive set of observations which are currently not available. First-order differences between the months with large (March 2012 and February 2013) and small (February 2012 and March 2013) SST diurnal changes are consistent with the wind measurements at DWS (Figure 12), SST day-night differences being anticorrelated with average wind intensity. On the other hand, it is unclear why wind differences of the order of $0.5 \mathrm{~m} \mathrm{~s}^{-1}$ (at DWS) have such an important impact on the SST diurnal cycle amplitude. Our experience at sea in the SSUC suggests that strong local differences exist in the amplitude and structure of the diurnal wind cycle. To illustrate this, we compute and compare wind diurnal cycles averaged over a set of periods during which the wind observations from $\mathrm{R} / \mathrm{V}$ weather stations were almost continuously available somewhere in the area $13^{\circ} 40^{\prime} \mathrm{N}-14^{\circ} 30^{\prime} \mathrm{N}$ and $17^{\circ} 30^{\prime} \mathrm{W}-16^{\circ} 55^{\prime} \mathrm{W}$ : 8-16 March 2012; 21 February 2013 to 3 March 2013; 6-18 March 2013. Wind diurnal cycles measured by the ship (hereafter SWS), Dakar and Banjul weather stations are shown in Figure 13. Despite a similar tendency for backing (respectively, veering) from approximately 10 to 2 A.M. (respectively, 2 to 10 A.M.), details of the SWS and DWS wind cycles differ strongly. Wind amplitudes are roughly out of phase with a wind maximum (respectively, minimum around) 2 P.M. at DWS (respectively, 12 P.M. at SWS). The westerly tendency for SWS is also much more pronounced, possibly as a consequence of a sea breeze effect. The BWS wind diurnal cycle is the most similar to that for SWS with a wind intensity minimum in the afternoon but shifts in wind direction during the night and afternoon are even more pronounced. Because it is located inland, local site effects may be important at BWS. A weather buoy deployed over the shelf would provide invaluable observations to further investigate the issue.

\subsection{Toward a Taxonomy of SSUC States and Features}

As a result of considerable averaging, the analyses presented thus far overshadow the SSUC range of variability. We shall now discuss several carefully chosen SST images encountered in the MODIS archive for the seasons 2006-2012 in an attempt to classify recurrent features that add complexity to the SST state. The 

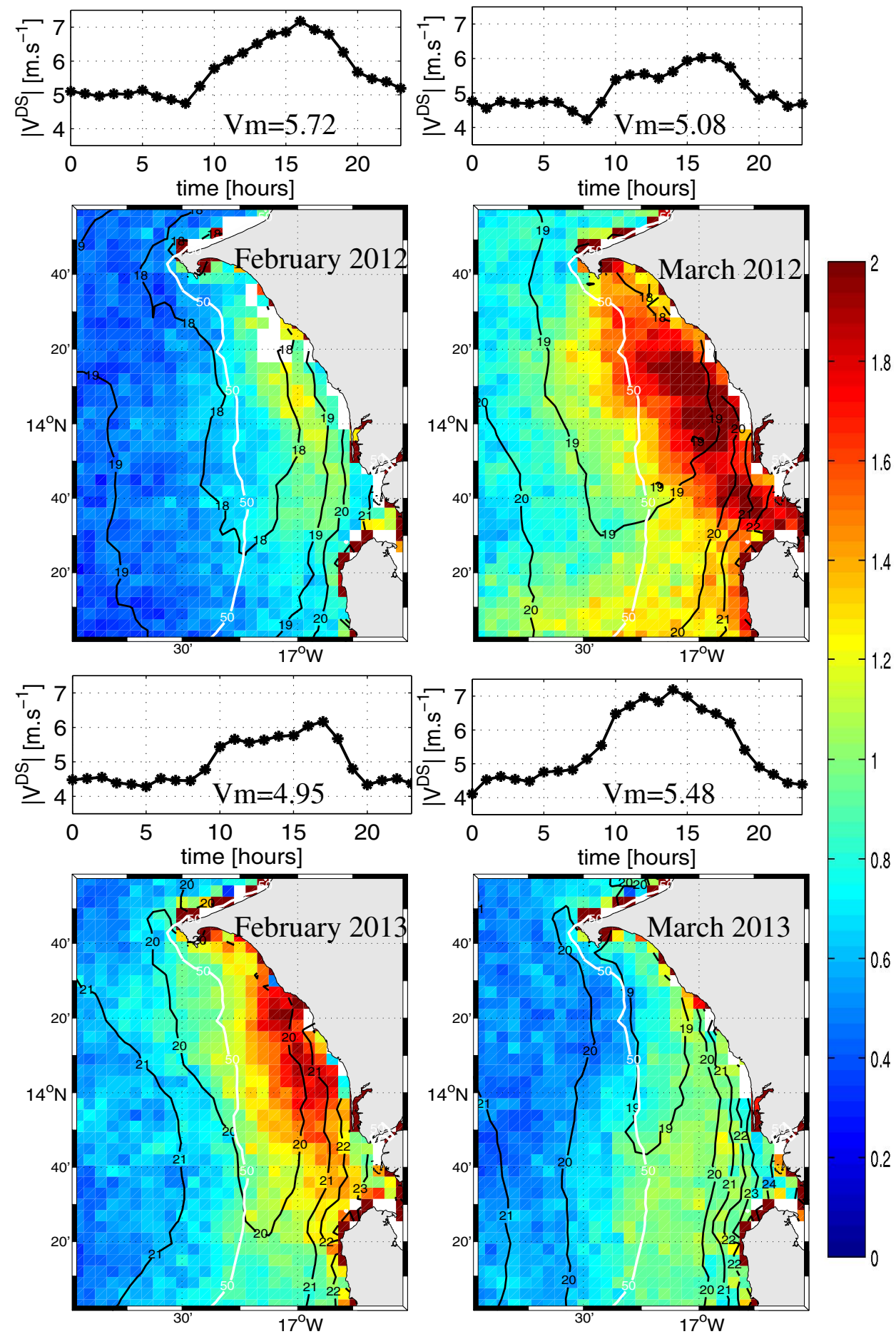

Figure 12. ( $a, b, e$, and $f$ ) Diurnal cycle of wind speed at Dakar Weather Station (average wind speed $V_{m}$ is also given for each month and ( $c$, $\mathrm{d}, \mathrm{g}$, and $\mathrm{h}$ ) peak-to-peak amplitude of the SST diurnal cycle over the SSUC. Averages for the months of February and March 2012 and 2013 are presented. The $50 \mathrm{~m}$ isobath and several isotherms are shown as white and black lines, respectively, in Figures 12c, 12d, 12g, and 12h.

premise of this qualitative approach is that it will provide a useful framework for the investigation of SSUC dynamics and variability, including with in situ observations.

Some of this variability is certainly directly attributable to the spatiotemporal wind details which we are not able to account for, given the limitations of our wind observations. Individual SST images also suggest the importance of the SSUC intrinsic turbulent activity, albeit less so than in other upwelling centers. 

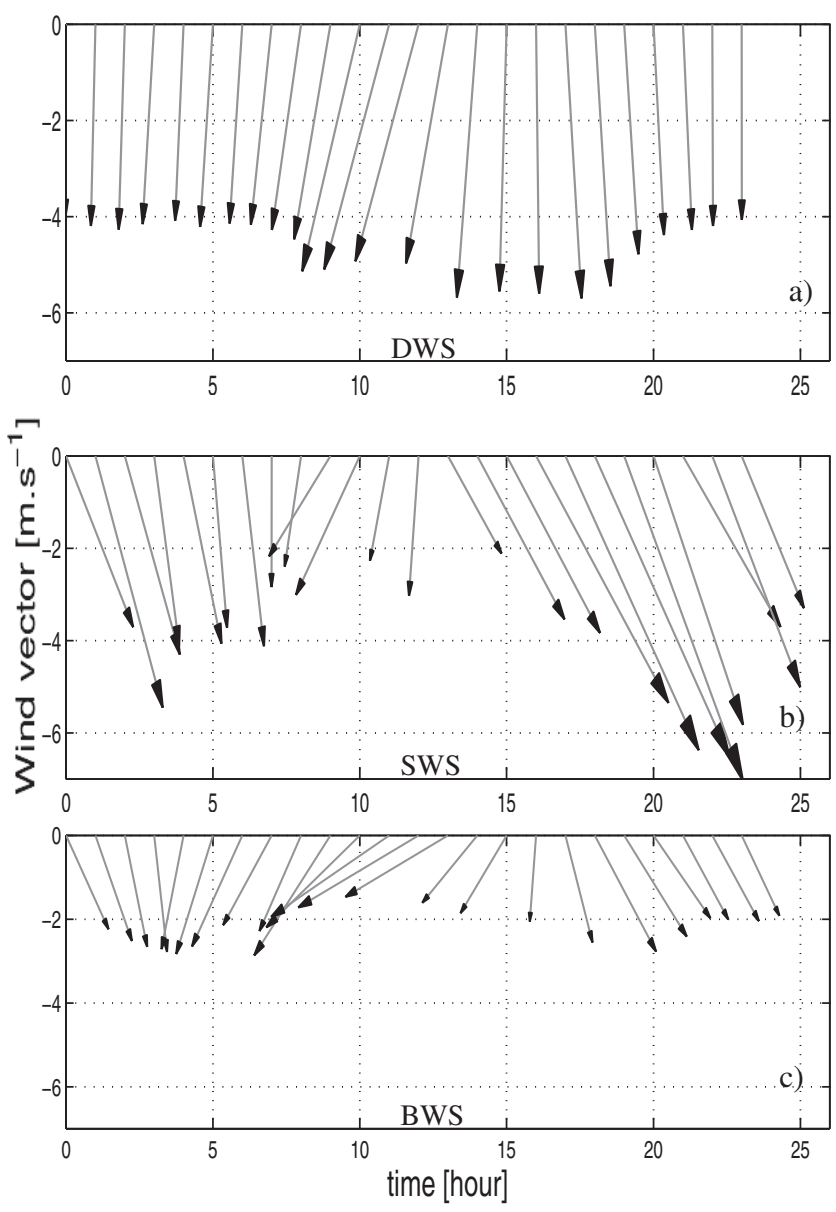

Figure 13. Wind vector diurnal cycle at the weather stations of (a) Dakar-Yoff and (c) Banjul and (b) from in situ measurements with marine weather stations mounted on R/V Suroît or Antéa present in the SSUC (only measurements in the box $13^{\circ} 40^{\prime} \mathrm{N}-$ $14^{\circ} 30^{\prime} \mathrm{N}$ and $17^{\circ} 30^{\prime} \mathrm{W}-16^{\circ} 55^{\prime} \mathrm{W}$ are used). In each case, time averaging is over the same $\sim 30$ days during which field experiments were taking place in the SSUC: $8-16$ March 2012; 21 February 2013 to 3 March 2013; 6-18 March 2013.
3.4.1. Northern-Southern Senegal Connection/Separation

Northern and southern Senegal upwelling sectors have traditionally been described as separated, with the Cape Verde headland being the physical barrier. The frequent occurrence of a filament flushing the northern upwelled waters offshore at Cape Verde, sometimes with the formation of a cold cyclonic eddy [Alpers et al., 2013] exemplifies this separation (e.g., see Figure 2c). A different type of situation where separation is also evident corresponds to Figures $2 \mathrm{~g}, 2 \mathrm{~h}$, and $2 \mathrm{i}$. In these plots, a warm core mesoscale structure with a typical horizontal scale $\sim 50-100 \mathrm{~km}$ (see below for further elaboration) hugs the headland and effectively isolates the northern and southern domains, at least in terms of SST. In Figure 2b, a mesoscale structure is also noticeable in the vicinity of Cape Verde but its signature is much weaker and does not reach the coastline. As a consequence, a continuous ribbon of cold $\left(16-17^{\circ} \mathrm{C}\right)$ water borders Cape Verde and the north-south exchanges of surface waters cannot be ruled out. SST patterns of Figure $2 f$ are more clearly suggestive of such exchanges.

Indications of (limited) surface water exchanges between the northern

and southern sectors are also provided by analyses presented above. We have already mentioned the patch of elevated PDF of minimum SST location that emanates from the northern tip of Cape Verde in FebrauaryMay (Figure 8). Close examination of the SST climatology for April (Figure 3) and to a lesser extent March reveals similar hints of south to north pathways for surface waters. For April, the shape of isotherms is consistent with cold water advected around western Cape Verde. Figure $2 \mathrm{k}$ is one of the examples we have found where satellite SST strongly suggests northward advection of cold water upwelled within a few kilometers of Cape Verde.

Several elements thus point to the influence of the poleward Mauritanian current (introduced in section 1) in shaping the limited exchanges of upwelling surface waters between the northern and southern upwelling sectors. SST images only suggest short-range exchanges but SST modifications by air-sea fluxes and mixing certainly limit our ability to track water pathways. Around 100 surface drifters were released in Senegalese coastal waters by the COCES/COCES2 programs (P.-M. Poulain, personal communication, 2014) and might be helpful to address this issue more thoroughly.

\subsubsection{Mesoscale Activity and Offshore Pathways for SSUC Upwelled Water}

A common deviation from the canonical state seen in Figures 3 and 9 corresponds to the situations of Figures 2b, 2g, 2h, and 2i: a warm anticyclonic structure (Cape Verde Anticyclone, hereafter CVA) is located right off the Cape Verde headland, sometimes so close that topographic influence on the structure becomes evident (Figure 2g); the shape and size of the CVA (radius of the order of tens of $\mathrm{km}$ ) induces an 
upwelling filament that advects cold upwelled water across the shelf break around $14^{\circ} \mathrm{N}$ (Figures $2 \mathrm{~b}, 2 \mathrm{~g}, 2 \mathrm{~h}$, and 2i). The orientation of the flow in the filament is generally toward the northwest. It is reminiscent of the traditional roll-ups and filament formations that take place in nonlinear regimes of barotropic-baroclinic instability of boundary currents [e.g., Capet and Carton, 2004]. We attribute the filament orientation to the presence of an intense shear zone between the poleward Mauritanian current and the inshore equatorward upwelling flow. Over the shelf, the flow curvature induced by the CVA north of $14^{\circ} \mathrm{N}$ (see Figures $2 \mathrm{~g}$ and $2 \mathrm{i}$, for example) could explain the northern comma-shape pattern found in Figures 8 and 11. The ability of warm offshore water to occasionally impinge over the shelf is not inconsistent with recent simulations of thermohaline intrusions in an unstable shelf break front [Wang and Jordi, 2011].

The presence of a well-developed anticyclone in the immediate vicinity of Cape Verde headland, such as in Figure $2 \mathrm{~g}$ is incompatible with the concomitant presence of the upwelling filament funneling cold water offshore north of Dakar, e.g., as observed in Figure 2c. Conditions most favorable to the establishment of a CVA may thus include dominant northwesterly winds for which upwelling is weak or absent north of Dakar (as a consequence of the distinct coastline orientation) [Roy, 1989]. On the other hand, wind orientations around the time when MODIS scenes presented in Figure 2 were taken (approximately three inertial periods as shown but we have also considered two and four) are not particularly supportive of this hypothesis. Processes underlying the development of CVAs are currently investigated through model simulations.

Other types of mesoscale perturbations are also observed. In Figure $2 \mathrm{c}, 18-19^{\circ} \mathrm{C}$ waters have been pushed $50 \mathrm{~km}$ or more off Cape Verde and a relatively straight front separates them from colder upwelling waters. Some upwelling water is shed off the shelf around $13^{\circ}-13^{\circ} 30^{\prime} \mathrm{N}$ in a seemingly sluggish upwelling filament. In cases where a filament is present at $\sim 14^{\circ} \mathrm{N}$ it is frequently accompanied by a weaker filament located further south around $13^{\circ}$ (Figures $2 \mathrm{~b}$ and $2 \mathrm{i}$ ). Modulations in the amplitude of the mesoscale disturbances (e.g., as characterized by the offshore extent of the upwelling filaments or horizontal scales of the warm meanders/eddies disrupting the front between upwelling and offshore waters) is not always consistent with the wind history over a few inertial periods (compare Figures $2 \mathrm{f}$ and $2 \mathrm{~b}-2 \mathrm{~d}$ and $2 \mathrm{~g}$ ) although the weakest winds tend to be associated with SST images suggestive of weak eddy variability (Figures $2 \mathrm{e}$ and $2 \mathrm{~h}$ ) and vice versa (Figures $2 \mathrm{~b}, 2 \mathrm{c}$, and $2 \mathrm{f}$ ).

Overall, the impression drawn from this limited set of images (but consistent with the inspection of many others) is that the instability regimes of the current system off southern Senegal are strongly influenced by the presence of Cape Verde, in a way that tends to constrain the location of the main exit pathways for SSUC upwelling water around $14^{\circ} \mathrm{N}$. This is a useful SSUC characteristic to observationally quantify export off the shelf.

\subsubsection{Alongshore Decay of the Upwelling SST Signal}

The southward extension of the SST upwelling signal is highly variable (compare Figures $2 \mathrm{~b}$ and 2e). Although a clear relationship between alongshore wind intensity and the size of the upwelling plume (defined by a given isocontour) emerged from the compositing presented in section 3.2 (Figure 9) some extreme situations in terms of southward extension of the plume are not associated with anomalously strong winds at DWS. Such a situation with surface waters colder than $17^{\circ}$ found all the way to $11^{\circ} \mathrm{N}$ and resembling Figure 2c over the SSUC was experienced in March 2014 during a field experiment. Wind observations for that period both from ASCAT and from in situ measurements are indicative of weaker than average north-south wind dropoff, as opposed to stronger winds than average at DWS. Remotely forced upwelling (or downwelling) signals associated with poleward propagation of coastal trapped waves further complicates the issue, as discussed in relation to the late upwelling transition phase in section 3.1. Ambient stratification, wind history over several days to weeks, and larger-scale circulation are other factors that a priori impact the alongshore structure of the upwelling plume.

\subsubsection{Nearshore Circulation}

Although friction plays an increasingly dominant role in the shallow waters, the structure of the nearshore front south of $14^{\circ} 30^{\prime} \mathrm{N}$ is such that thermal wind balance may counterbalance wind effects and impose a net northward flow at least some of the time. Neglecting salinity gradients in the area [Touré, 1983] and assuming a well-mixed water column we have 


$$
\Delta v=\frac{g H}{\rho_{0} f} \frac{\Delta \rho_{f}}{L_{f}}
$$

where $\Delta v$ is the thermal wind shear from bottom to surface, $H$ is the typical depth of the nearshore frontal zone, $\Delta \rho_{f}$ is the density difference across the front and $L_{f}$ its typical scale. Using $H=15 \mathrm{~m}, \Delta \rho_{f}=0.8 \mathrm{~kg} / \mathrm{m}^{3}$ (corresponding to $4^{\circ} \mathrm{C}$, see Figure 10b) and $L_{f}=20 \mathrm{~km}$ we find $\Delta v=17 \mathrm{~cm} \mathrm{~s}^{-1}$, i.e., somewhat larger than depth-averaged alongshore Ekman velocities $v_{E} \sim \tau_{y} /\left(\rho_{0} f H\right) \approx 11 \mathrm{~cm} \mathrm{~s}^{-1}$ in upwelling event conditions $\left(\tau_{y}=0.06 \mathrm{~N} \mathrm{~m}^{-2}\right)$. In low wind conditions, $\Delta \rho_{f}$ is reduced (by a factor of $2-3$ ) but Ekman velocities are also much weaker (wind stress is reduced by a factor of 3-4). Situations most favorable to a northward flow are expected to occur shortly after wind events when the coastal temperature front remains well marked, whereas Ekman currents slow down and the relaxation of pressure gradients should also contribute to the northward flow.

Obviously, a northward surface flow cannot be found north of Cape Gombaru where the coastal front is no longer present and coastal upwelling should be accompanied by a southward jet. Some flow modification must thus take place around $14^{\circ} 10^{\prime} \mathrm{N}-14^{\circ} 30^{\prime} \mathrm{N}$ to maintain non divergence. We hypothesize that the termination of the northward flow at the coastal front leads to westward velocities and, consequently, injection of coastal water into the upwelling zone. Evidences for this are relatively limited but some daytime MODIS scenes exhibit SST patterns consistent with this flow structure (see Figures $2 \mathrm{j}$ and $2 \mathrm{l}$ ). The discontinuity seen in PDFs of SST minima is also consistent with it (although it could be due to the effects of Cape Verde anticyclones on the shelf circulation as mentioned above). Note that the reasoning does not require a northward flow to exist and differential southward advection north and south of Cape Gombaru would suffice to imply a localized westward flow.

\section{Discussion and Conclusion}

The view on the SSUC offered by this study is based on the analysis of SST, a nonconservative tracer strongly affected by air-sea fluxes and having complex links with subsurface shelf dynamics and its thermohaline structure. This brings important limitations to the approach but our focus is on upwelling dynamics which is generally well reflected in SST. Furthermore, relying primarily on nighttime images ensures that SST is representative of temperature in a 10-30 m mixed layer. The number of images uncontaminated by clouds or aerosols ( $\gtrsim 1500$ ) gives us access to fine-scale details of the SSUC dynamical functioning that are by construction (using monthly or seasonal averaging) statistically important.

The SST annual cycle can be simply described in terms of expansion (from October-November to February) and rapid retraction (May) of the cold water tongue present over the southern Senegal-Gambia shelf. Similarly, upwelling and relaxation events with time scales of 3-10 days modulate the upwelling intensity and manifest themselves, on average, as expansion/retraction phases of the upwelling tongue. The magnitude of the SST (and wind) diurnal cycle can be large inshore of the $50 \mathrm{~m}$ isobath. Consequences on heat air-sea fluxes and the strength of the atmosphere-ocean coupled processes are unclear but presumably important. Net heat flux errors in the SSUC estimated by Clayson and Bogdanoff [2013] are in slight excess of $5 \mathrm{~W} \mathrm{~m}^{-2}$ during the upwelling season (their Figure 4). We suspect that their global analysis underestimates local coastal effects such as revealed in Figure 12.

South of $14^{\circ} 30^{\prime} \mathrm{N}$ numerous SST images consistently reveal intermittent upwelling in the 3-5 pixels closest to shore, roughly inshore of the $10 \mathrm{~m}$ isobath. Such truly coastal upwelling occurs sometimes in conjunction with well-marked midshelf SST minima, during periods characterized by sustained upwelling winds (at DWS), mainly before February. Winds with a strong easterly component seem conducive to this type of situation as expected from inner shelf in situ observations reported by, e.g., Lentz and Fewings [2012]. However, our analyses of this aspect remain inconclusive, perhaps due to easterly winds events which could not be adequately identified (easterly winds are not well captured at DWS and are expected to have a large level of uncertainty and spatial variability over the SSUC as indicated by the diurnal cycle analysis).

Based on the form taken by Ekman drift in shallow waters where surface and bottom boundary processes can interact, Estrade et al. [2008] have proposed a conceptual model for upwelling dynamics on wide shelves such as the SSUC. In this model cross-shore Ekman transport is retarded over the inner shelf where surface and bottom mixed layers are merged; and upwelling takes place offshore of that zone where Ekman 


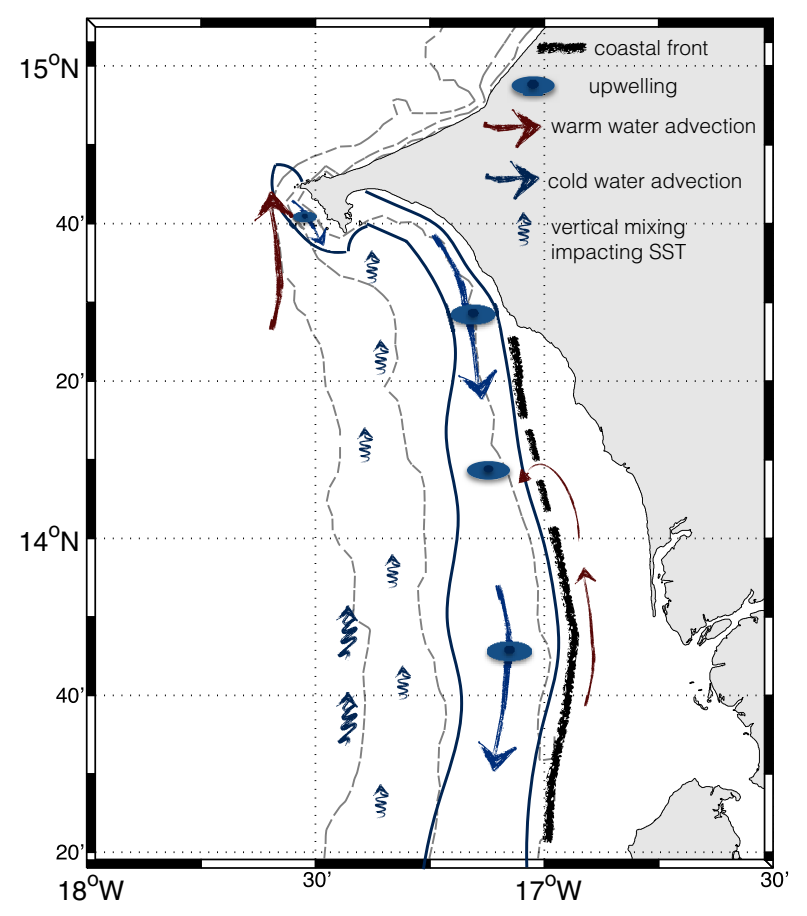

Figure 14. Schematic representation of the key dynamical elements apparent during the February to April upwelling period from our analysis of MODIS L2 SST patterns. Sinuous thin lines delineate the upwelling zones. Gray dashed lines represent the 20,50 , and $100 \mathrm{~m}$ isobaths. The latter roughly coincides with the shelf break. Thick black lines indicate the position of the coastal front which is represented as partly interrupted around $14^{\circ} 10^{\prime} \mathrm{N}$. We tentatively relate this to the bifurcation of a (possibly intermittent) northward flow of warm coastal water (red arrows). Off the Cape Verde headland, interplay between the poleward flowing Mauritanian current (thick red arrow) and the localized coastal upwelling is often noticeable in MODIS SST images. Elevated probability of SST minimum presence at the shelf break under low wind conditions (Figure 11) is interpreted as a consequence of internal tide breaking. This effect is most evident in the southern part of the domain but may also be present in other parts of the shelf including just south of Dakar in the vicinity of the $50 \mathrm{~m}$ isobath (see Figure 11, left). drift progressively returns to its normal orientation $90^{\circ}$ to the right of the wind. The seasonal displacement of SST minima over the shelf is broadly consistent with this model given the wind seasonal changes and its expected effects on boundary layer thickness (and inner-shelf width). On average, SST minima are found farthest from shore (around 30-50 $\mathrm{m}$ depth) in February-March when winds are the strongest and closest to the shore in the early part of the upwelling season when the wind speed is lowest.

On the other hand, some results and individual situations that are in apparent contradiction with this theory are also obtained. Importantly, low wind SST minima are often found as far offshore as the shelf break, suggesting that other processes may be at work. More generally, these offshore SST minima are not well marked, discontinuous, and they are most commonly found in the southern part of the domain where the wind is on average weakest (see Figure 15). Our interpretation is that cold surface water found at the shelf break arises from a combination of (i) intense internal tide mixing as documented for non upwelling shelves [Sharples et al., 2007], (ii) water upwelled in the north being advected obliquely to the shelf in specific meso-

scale/wind conditions (Figures 2c, 2d, 2f, 2g, and 2k). Field measurements in support of (i) were collected in 2013 (Capet et al., in preparation). Conversely, our analyses (and recent in situ observations) do not support the existence of a subinertial upwelling cell at the shelf break as advocated in Roy [1998], for example.

Previously unknown details of the SSUC dynamics revealed by our analyses of the late upwelling period (February-April) are summarized in Figure 14. Cooling of surface waters over the shelf break and outer shelf is a prominent feature in relaxation conditions that we relate to internal tide breaking. Sustained coastal upwelling occurs along the western edge of Cape Verde during the second half of the upwelling season. The associated circulation strongly interacts with the Mauritanian current heading north which seems to affect the fate of upwelled waters. Finally, the coastal shelf front on the inshore side of the SST minima is represented with a discontinuity that may be related to a confluence of the inner-shelf circulation near $14^{\circ} \mathrm{N}-14^{\circ} 10^{\prime} \mathrm{N}$ (although the influence of a mesoscale anticyclone frequently observed in the northwestern part of the SSUC may extend far enough into the shelf area to explain the discontinuity).

Overall, the SSUC exhibits persistent and recurrent SST patterns during the upwelling season and we see this as a consequence of the limited variability of the circulation. Important reasons for this would be the regularity of the wind forcing on intraseasonal and also interannual time scales (as we have found year-toyear differences between cumulative upwelling indices [Bograd et al., 2009] computed using DWS observations can reach $20 \%$ but are most often below 10\%); the north-south invariance of the bathymetry south of $14^{\circ} 30^{\prime} \mathrm{N}$ and the general weakness of the intrinsic variability. Subinertial intrinsic variability (mesoscale and submesoscale) is ubiquitous in upwelling systems but its intensity varies depending on several factors, wind 


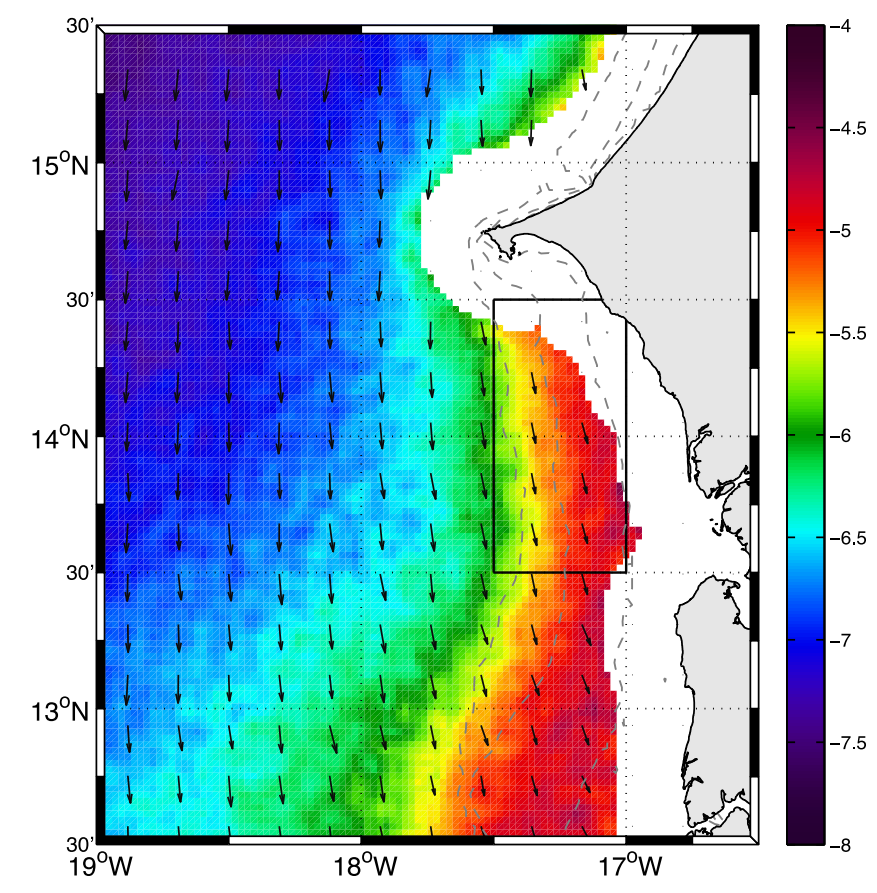

Figure 15. Climatological QuikSCAT wind vector and meridional wind (color, in $\mathrm{m} \mathrm{s}^{-1}$ ) fields for the sustained upwelling period February-April. Wind fields are constructed in such a way that the scatterometer blind zone (area in white) is as small as possible (see Appendix A, for details). Nearshore wind dropoff is evident as well as a reduction in wind intensity toward the south. On the other hand, no orographic effect induced by the Cape Verde peninsula is visible. The averaging box used to compute $\mathbf{V}^{\mathrm{QK}}$ in section 2 is delimited using solid black lines. Isobaths 20,50 , and $100 \mathrm{~m}$ are shown as gray lines.

differs from those usually found off upwelling shelves because the influence of the poleward Mauritanian current extends all the way to the surface.

Our analyses and findings highlight the overall regularity and stability of the SSUC dynamical functioning but they also reveal complexity in the upwelling structure (and hence presumably the spatial distribution of nutrient delivery to the shelf). In situ verifications are needed. The ecosystemic implications, e.g., for the ecological functioning of the SSUC sardinella nursery (recruitment, habitat structure and variability) also need to be explored via in situ approaches.

\section{Appendix A: Wind Field Structure in the SSUC}

To gain insight into the detailed spatial structure of the wind field, we carefully map and time-average the QuikSCAT wind observations so as to limit the extent of the blind zone. Along swath L2B QuikSCAT wind data are given at wind vector cells (WVC) of $12.5 \times 12.5 \mathrm{~km}$. Some uncertainty exists over the position of the WVC center but because we are interested in climatological winds which implies considerable time averaging we have gridded the entire data set at $4 \mathrm{~km}$ resolution with each individual QuikSCAT measurement being assigned to the grid pixel in which its WVC center falls. In doing, we enhance horizontal resolution (and reduce the blind zone extent) compared to products such as QuikSCOW [Risien and Chelton, 2008] (gridded at $25 \times 25 \mathrm{~km}$ ), albeit at the price of increased spatial noise. The resulting wind vector and meridional wind fields for the period February-April are presented in Figure 15. The wind cross-shore structure (dropoff when approaching the shore) typical of many upwelling regions [Capet et al., 2004] is noticeable. On the other hand, the type of expansion fan structure frequently found in the vicinity of headlands, e.g., off central California [Winant et al., 1988; Enriquez and Friehe, 1995] is absent. (A wind speed increase in the immediate proximity of the Cape Verde peninsula cannot be ruled out but its magnitude must be very limited to have no signature outside the blind zone.) We relate this to the limited terrain elevation (below $\sim 100 \mathrm{~m}$ in the senegalese coastal area and in particular the Cape Verde peninsula) and generally smooth 
topography (see http://www.floodmap.net/Elevation/CountryElevationMap/?ct=SN). Differences in wind orientation north and south of the Cape Verde peninsula are also minor. The results are similar for the early and late upwelling seasons. From this, we conclude that systematic orographic effects induced by the Cape Verde peninsula are weak (on the scales of tens of kilometers and more) which strengthens and provides insight into the results of section 2 with a good level of agreement between $\mathbf{V}^{Q K}$ and $\mathbf{V}^{D S}$.

\section{Acknowledgments}

We acknowledge financial support from IRD through the AWA and LMI ECLAIRS program, from LEFE-INSU FUSE, and from FP7 PREFACE. S.N. is supported by the Programme doctoral international modélisation des systèmes complexes UPMC/IRD. We are grateful to the captains and crews of R/V Suroit and Antéa for their help. We thank F. Colas, H. Demarcq, L. Mortier, M. Wade, and S. Nicholson for their help and comments. Three anonymous reviewers greatly helped improve this study. Data SST MODIS are available (ordering "Level 2" data) at http://oceancolor.gsfc.nasa.gov/cgi/ browse.pl. QuikSCAT data are available (level 2) at ftp://podaac-

ftp.jpl.nasa.gov/allData/quikscat/ L2B12/v2/. Wind data from Dakar weather station were downloaded at www.ogimet.com/metars.phtml.en. The data from the EUMETSAT Satellite Application Facility on Ocean and Sea Ice used in this study are accessible through the SAF's homepage: http:// www.osi-saf.org. The altimeter data were produced by Ssalto/Duacs and distributed by Aviso with support from Cnes.

\section{References}

Alpers, W., P. Brandt, A. Lazar, D. Dagorne, B. Sow, S. Faye, M. W. Hansen, A. Rubino, P.-M. Poulain, and P. Brehmer (2013), A small-scale oceanic eddy off the coast of West Africa studied by multi-sensor satellite and surface drifter data, Remote Sens. Environ., 129, $132-143$.

Arístegui, J., E. D. Barton, X. A. Álvarez-Salgado, A. M. P. Santos, F. G. Figueiras, S. Kifani, S. Hernández-León, E. Mason, E. Machú and H. Demarcq (2009), Sub-regional ecosystem variability in the canary current upwelling, Prog. Oceanogr., 83, 33-48.

Bakun, A., and C. S. Nelson (1991), The seasonal cycle of wind-stress curl in subtropical eastern boundary current regions, J. Phys. Oceanogr., $21,1815-1834$

Barton, E. (1989), The poleward undercurrent on the eastern boundary of the subtropical North Atlantic, in Poleward Flows Along Eastern Ocean Boundaries, pp. 82-95, Springer, N. Y.

Barton, E. D. (1998), Eastern boundary of the north Atlantic: Northwest Africa and Iberia. Coastal segment (18, e), in The Sea, vol. 11, pp. 633-657, John Wiley, N. Y.

Benazzouz, A., S. Mordane, A. Orbi, M. Chagdali, K. Hilmi, A. Atillah, J. L. Pelegrí, and H. Demarcq (2014), An improved coastal upwelling index from sea surface temperature using satellite-based approach. The case of the Canary Current upwelling system, Cont. Shelf Res., $81,38-54$.

Bograd, S. J., I. Schroeder, N. Sarkar, X. Qiu, W. J. Sydeman, and F. B. Schwing (2009), Phenology of coastal upwelling in the California Current, Geophys. Res. Lett., 36, L01602, doi:10.1029/2008GL035933.

Capet, X., and X. Carton (2004), Nonlinear regimes of baroclinic boundary currents, J. Phys. Oceanogr., 34, 1400-1409.

Capet, X., P. Marchesiello, and J. C. McWilliams (2004), Upwelling response to coastal wind profiles, Geophys. Res. Lett., 31, L13311, doi: 10.1029/2004GL020123.

Castelao, R., T. Mavor, J. Barth, and L. Breaker (2006), Sea surface temperature fronts in the California Current System from geostationary satellite observations, J. Geophys. Res., 111, C09026, doi:10.1029/2006JC003541.

Clayson, C. A., and A. S. Bogdanoff (2013), The effect of diurnal sea surface temperature warming on climatological air-sea fluxes, J. Clim., $26,2546-2556$.

Cury, P., and C. Roy (1991), Pêcheries Ouest Africaines: Variabilité, Instabilité et Changement, edited by Cury, Philippe, Roy and Claude, pp. 525, ORSTOM, Paris.

Demarcq, H., and V. Faure (2000), Coastal upwelling and associated retention indices derived from satellite SST application to Octopus vulgaris recruitment, Oceanol. Acta, 23, 391-408.

Donlon, C. J., M. Martin, J. Stark, J. Roberts-Jones, E. Fiedler, and W. Wimmer (2012), The operational sea surface temperature and sea ice analysis (OSTIA) system, Remote Sens. Environ., 116, 140-158.

Enriquez, A., and C. Friehe (1995), Effect of wind stress and wind stress curl variability on coastal upwelling, J. Phys. Oceanogr., 25, 16511671.

Estrade, P., P. Marchesiello, D. Verdière, A. Colin, and C. Roy (2008), Cross-shelf structure of coastal upwelling: A two dimensional extension of Ekman's theory and a mechanism for inner shelf upwelling shut down, J. Mar. Res., 66(5), 589-616.

Gentemann, C. L., P. J. Minnett, and B. Ward (2009), Profiles of ocean surface heating (POSH): A new model of upper ocean diurnal warming, J. Geophys. Res., 114, C07017, doi:10.1029/2008JC004825.

Graham, W. M., and J. L. Largier (1997), Upwelling shadows as nearshore retention sites: The example of northern Monterey Bay, Cont. Shelf Res., 17, 509-532.

Koračin, D., C. E. Dorman, and E. P. Dever (2004), Coastal perturbations of marine-layer winds, wind stress, and wind stress curl along California and Baja California in June 1999, J. Phys. Oceanogr., 34, 1152-1173.

Lamb, J., and W. Peterson (2005), Ecological zonation of zooplankton in the COAST study region off central Oregon in June and August 2001 with consideration of retention mechanisms, J. Geophys. Res., 110, C10S15, doi:10.1029/2004JC002520.

Le Borgne, P., H. Roquet, and C. Merchant (2011), Estimation of sea surface temperature from the Spinning Enhanced Visible and Infrared Imager, improved using numerical weather prediction, Remote Sens. Environ., 115(1), 55-65.

Lentz, S. J. (1994), Current dynamics over the northern California inner shelf, J. Phys. Oceanogr., 24(12), 2461-2478.

Lentz, S. J., and M. R. Fewings (2012), The wind- and wave-driven inner-shelf circulation, Annu. Rev. Mar. Sci., 4, 317-343.

Marchesiello, P., and P. Estrade (2009), Eddy activity and mixing in upwelling systems: A comparative study of northwest Africa and California regions, Int. J. Earth Sci., 98, 299-308.

Merchant, C., M. Filipiak, P. Le Borgne, H. Roquet, E. Autret, J.-F. Piolle, and S. Lavender (2008), Diurnal warm-layer events in the western Mediterranean and European shelf seas, Geophys. Res. Lett., 35, L04601, doi:10.1029/2007GL033071.

Meunier, T., E. D. Barton, B. Barreiro, and R. Torres (2012), Upwelling filaments off Cap Blanc: Interaction of the NW African upwelling current and the Cape Verde frontal zone eddy field?, J. Geophys. Res., 117, C08031, doi:10.1029/2012JC007905.

Nieto, K., H. Demarcq, and S. McClatchie (2012), Mesoscale frontal structures in the Canary Upwelling System: New front and filament detection algorithms applied to spatial and temporal patterns, Remote Sens. Environ., 123, 339-346.

Peña-Izquierdo, J., J. L. Pelegrí, M. V. Pastor, P. Castellanos, M. Emelianov, M. Gasser, J. Salvador, and E. Vázquez-Domínguez(2012), The continental slope current system between Cape Verde and the Canary Islands, Sci. Mar., 76, 65-78.

Pringle, J. M., and K. Riser (2003), Remotely forced nearshore upwelling in Southern California, J. Geophys. Res., 108(C4), 3131, doi:10.1029/ $2002 J C 001447$

Ramp, S. R., P. F. Jessen, K. H. Brink, P. P. Niiler, F. L. Daggett, and J. S. Best (1991), The physical structure of cold filaments near Point Arena, California, during June 1987, J. Geophys. Res., 96, 14,859-14,883.

Risien, C. M., and D. B. Chelton (2008), A global climatology of surface wind and wind stress fields from eight years of QuikSCAT scatterometer data, J. Phys. Oceanogr., 38, 2379-2413.

Roughan, M., N. Garfield, J. Largier, E. Dever, C. Dorman, D. Peterson, and J. Dorman (2006), Transport and retention in an upwelling region: The role of across-shelf structure, Deep Sea Res., Part II, 53(25), 2931-2955. 
Roy, C. (1989), Fluctuation of wind and upwelling variability off the Senegalese coast, Oceanol. Acta, 12, 361-369.

Roy, C. (1998), An upwelling-induced retention area off Senegal: A mechanism to link upwelling and retention processes, S. Afr. J. Mar. Sci., $19,89-98$.

Roy, C., P. Cury, A. Fontana and H. Belvèze (1989), Stratégies spatio-temporelles de la reproduction des clupéidés des zones d'upwelling d'Afrique de l'Ouest, Aquat. Living Resour., 2, 21-29.

Savtchenko, A., D. Ouzounov, S. Ahmad, J. Acker, G. Leptoukh, J. Koziana, and D. Nickless (2004), Terra and aqua MODIS products available from NASA GES DAAC, Adv. Space Res., 34, 710-714.

Sharples, J., et al. (2007), Spring-neap modulation of internal tide mixing and vertical nitrate fluxes at a shelf edge in summer, Limnol. Oceanogr. Methods, 52, 1735-1747.

Touré, D. (1983), Contribution à l'étude de l'upwelling de la baie de gorée (dakar-sénégal) et de ses conséquences sur le développement de la biomasse phytoplanclonique, vol. 93, 186 pp., Cent. de Rech. Océanogr., Dakar.

Wang, D.-P., and A. Jordi (2011), Surface frontogenesis and thermohaline intrusion in a shelfbreak front, Ocean Modell., 38, $161-170$.

Winant, C., D. Dorman, C. Friehe, and R. Beardsley (1988), The marine layer off Northern California: An example of supercritical channel flow, J. Atmos. Sci., 45, 3588-3605.

Woodson, C., et al. (2007), Local diurnal upwelling driven by sea breezes in northern Monterey Bay, Cont. Shelf Res., 27, 2289-2302. 